\title{
EVALUATION OF THE PREDICTIVE CAPABILITY OF THE FINITE ELEMENT \\ METHOD: II, PROJECT SALT VAULT - THERMO/VISCOELASTIC SIMULATION
}

\author{
Submitted To \\ Office of Waste Isolation \\ Oak Ridge, Tennessee \\ operated by \\ Union Carbide Corporation \\ Nuclear Division \\ for the \\ Department of Energy
}

By

Joe L. Ratigan

and

Gary D. Callahan

This report was prepared by RE/SPEC InC., under Subcontract No. 89Y-22303C with Union Carbide Corporation, Nuclear Division, under Contract No. W-7405-eng-26 with the Department of Energy. The subcontract was administered by the Office of Waste Isolation, Union Carbide Corporation, Nuclear Division.

March 17, 1978

(Revised and Resubmitted on July 28, 1978)

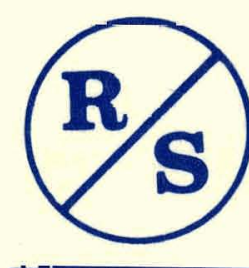

RE/SPEC INC.

P. O. BOX 725 - RAPID CITY, S. D. 57701 - 605/343-7868 


\section{DISCLAIMER}

This report was prepared as an account of work sponsored by an agency of the United States Government. Neither the United States Government nor any agency Thereof, nor any of their employees, makes any warranty, express or implied, or assumes any legal liability or responsibility for the accuracy, completeness, or usefulness of any information, apparatus, product, or process disclosed, or represents that its use would not infringe privately owned rights. Reference herein to any specific commercial product, process, or service by trade name, trademark, manufacturer, or otherwise does not necessarily constitute or imply its endorsement, recommendation, or favoring by the United States Government or any agency thereof. The views and opinions of authors expressed herein do not necessarily state or reflect those of the United States Government or any agency thereof. 


\section{DISCLAIMER}

Portions of this document may be illegible in electronic image products. Images are produced from the best available original document. 


\title{
EVALUATION OF THE PREDICTIVE CAPABILITY OF THE FINITE ELEMENT
}

\section{METHOD: II, PROJECT. SALT VAULT - THERPOPISCOELASTIC SIINULATION}

\author{
Submitted To \\ Office of Waste Isolation \\ Oak Ridge, Tennessee \\ operated by \\ Union Carbide Corporation \\ Nuclear Division \\ for the \\ Department of Energy
}

This report was prepared as an accoun of work United States Energ States nor the United States Department of Energy, not any of their employees, nor any of their any warranty, subcontractors, of their employees, makes liability ot responsess ot implied, or assumes any legal or usefulness of any inform for accuracy, completeness process disclosed, or information, apparatus, product or infringe privately owned resents that its use would not

\section{By}

Joe L. Ratigan

and

Gary D. Callahan

of

$R E / S P E C$ INC.

P. O. Borr 735

Rapid City, South Dakota

March 17, 1978

(Revised and Resubmitted on July 28, 1978)

This report was prepared as an account of work sponsored by the United states Covernment. Neither the United States nor the Department of Energy, nor any, of their employees, nor any of their contractors, subcontractors, or their employees, makes any warranty, express or implied, or assumes any legal liability or responsibility for the accuracy, completeness or usefulness of any information, apparatus, product or process disclosed, or represents that its use would not infringe privately owned rights. Any mention of trade names in this report is for reference purposes only and should not be construed as any manner of endorsement. 
FOREWORD

This report was prepared under a subcontract with Union Carbide Corporation, Nuclear Division, a DOE contractor. The subcontract was administered by the Office of Waste Isolation and is part of the National Waste Terminal storage (NWTS) Program. The principal objective of the NWTS Program is to provide facilities in various deep geologic formations at multiple locations in the United States which will safely dispose of commercial radioactive waste, which must be delivered to a Federal Repository for terminal storage. Some of the expected wastes produce both heat and radioactivity. This situation leads to many unique problems in rock mechanics. This report addresses a particular problem relative to the Rock Mechanics Program.

This overall objective of the OWI Rock Mechanics Program is to predict the response of a rock mass hosting a waste repository during its construction and operation, as well as the post-operational phase. The operational phase is expected to be approximately 20 years while the post-operational phase will last until the repository no longer poses any potential hazard to mankind, a period that may last several hundred thousand years. The Rock Mechanics Program is concerned with near field effects on mine stability as well as far field effects relative to the overall integrity of the geologic containment of waste.

In order to accomplish the objectives of the Rock Mechanics Program, numerical simulation, laboratory (including bench scale), and field. studies are under way. The laboratory and field studies provide input to the numerical simulations and also the opportunity for validation of the predictive capabilities of the computer codes. Ultimately, the computer codes will provide the predicted response of the host rock mass and thereby form an essential part of the overall Rock Mechanics Program.

The study provided herein presents an assessment of the predictive capability of a two dimensional finite element structural program by performing a simulation of the Project Salt Vault experiment and comparing the numerically computed deformations to those which were. measured during the experiment. The numcrical method is evaluated in addition to the geometric and chronological approximations and the salt characterization.

The technical contents of this report have been reviewed by $D r$. Paul F. Gnirk and Mr. Leo L. Van Sambeek, and the report was typed by Ms. Julie S. Annicchiarico. 
1. INTRODUCTION AND OBJECTIVES . .

2. DESCRIPTION OF PROJECT SALT VAULT 3

2.1: General Description and objectives 3

2.2. Instrumentation 4

2.3. Chronology. 4

3. FINITE ELEMENT MODELING 9

3.1. Geometric Approximation. 9

3.2: Chronology Approximation : $\quad 9$

3.3. Material Characterization 13

4. COMPARISON OF FINITE ELEMENT AND PROJECT SALT 16

VAULT RESULTS

4.1. Description of Finite Element Models 16

4.2. Room Convergence Prior to Heat Initiation. 20

4.3. Room Convergence After Heat Initiation 20

4.4. Floor UpliFt . . . . 27

4.5. Horizontal Pillar Deformation 40

5. COMPARISON OF UNIAXIAL PILLAR SHORTENING WITH ROOM . 48 CONVERGENCE

6. SUMMARY AND CONCLUSIONS . . 51.

LIST OF REFERENCES

APPENDIX: CORRELATION OF REPORT FIGURES WITH REFERENCE $9 \quad A-1$ 
2.1

Plan of Project Salt Vault Experimental Area.

2.2. Rock Mechanics Instrumentation Plan for Project

3.1 . Salt Vault (After Bradshaw and McClain, 1971). Experiment.

4. 1 .

Finite Element Mesh Ml. for Rooms 1 and 4 (Prior to Heating). and 4 .

4.7. Vertical Convergence in the Center of Rooms 2 and 3.

Vertical Convergence in Room 1 Near Pillar 1-2.

4.15. Flocr Uplift Profiles at Selected Times; . 31

4.16. Floor Uplift Profiles at Selected Times; Model M2-Room 1 .

4.17. Floor Uplift Profiles at selected Times; Mode1 M2-Room 4.

4.18. Floor Uplift profiles at Selected Times; Model M3-Room. 1 .

4.19. Flúl Uplift Profiles at selected Times; 
4.23. Floor Uplift Profiles in Room 2 and 3 Across

4.24. Floor Uplift Profiles in Room 2 and 3 Across

4.25. Floor Uplift Profiles in Rooms 2 and 3 Across the Heated Pillar (Front Section); Model M2.

4.26. Floor Uplift Profiles in Room 2 and 3 Across the Heated Pillar (Back Section); Model M3.

4.27. Floor Uplift Profiles in Room 2 and 3 Across the Heated Pillar (Mid-Section); Model M3. the Heated Pillar (Front Section); Model M3.

4.29. Horizontal Movement of Barrier Pillar Ribs.

4.30. Horizontal Movement of Pillar 1-2 into Room 1 With Extensometer Anchor Correction.

4.31. Horizontal Movement of Pillar 1-2 into Room 1 Without Extensometer Anchor Correction.

4.32. Horizontal Movement of Pillar 3-4 into Room 4 With Extensometer Anchor Correction.

4.33. Horizontal Movement of Pillar 3-4 into Room 4 Without Extensometer Anchor Correction.

4.34. Horizontal Movement of Pillar 1-2 into Room 2 With Extensometer Anchor Correction.

4.35. Horizontal Movement of Pillar 1-2 into Room 2 Without Extensometer Anchor Correction.

4.36. Horizontal Movement of Pillar 3-4 into Room 3 With Extensometer Anchor Correction.

4.37. Horizontal. Movement of Pillar 3-4 into Room 3 Without Extensometer Anchor Correction.

4.38. Horizontal Movement of Pillar 2-3 into Room 2. in Room 1 Near Pillar 1-2.

5.2. Comparison of Pillar 3-4 Shortening to Convergence in Room 4 Near Pillar 3-4.

5.3. Comparison of Pillar 2-3 Shortening to Convergence in Room 2 Near Pillar 2-3.

5.4. Comparison of Pillar 2-3 shortening to Convergence 


\section{LIST OF TABLES}

TABLE NO.

PAGE

2.1.

Chronology of Project Salt vault

8

3.1

Chronology of Simulated Events

3.2 .

Thermal and Mechanical Properties Utilized

4.1. in PSV Simulation 


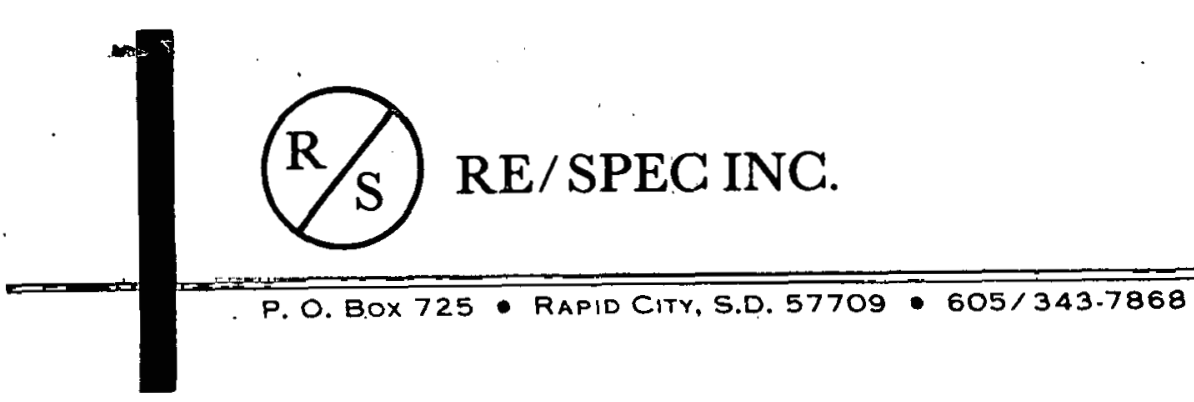

JuIy 28,1978

TECHNICAL MEMORANDUM REPORT RSI-0065

TO:

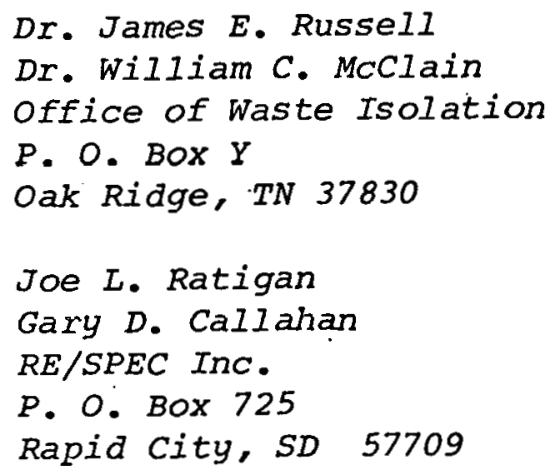

SUBJECT: Evaluation of the Predictive Capability of the Finite Element Method: II. Project Salt Vault-Thermoviscoelastic Simulation (Ref.: Union Carbide Corporation, Nuclear Division Subcontract No. $89 Y-22303 C, R S I / 001000 / F Y 78)$.

\section{INTRODUCTION AND OBTECTIVES}

Tize finite element method has been and is being extensively utilized in analysca of radioactive reprisituries. These analyses have included studies of the thermal and thermomechanical response of individual waste packages, storage rooms and pillars and regions which cover several repository depths and several repository diameters ${ }^{(1-4) *}$. The results of these analyses can be utilized to formulate or modify the emplacement concept, the storage room and pillar dimensions, and the stratigraphic siting of the repusitury.

Since the finite element method is a member of a class of approximate numerical techniques, it is necessary that the method be validated by comparing computed results to the results of actual laboratory or field situations. This comparison or validation has been utilized in the past in many instances for structures involving man-made materials and for excavations in geological mediums $(5,6)$. 
However, the validation has not been extensively utilized for comparison to phenomina observed in excavations in geological media involving rock which is heated above its ambient post-mining level. The mechanical response of a room-and-pillar configuration in a radioactive waste repository in.salt can be expected to be influenced by the thermal effects. Therefore, a validation of the finite element method involving both excavation and thermal loading is essential.

The purpose of this study is to assess the predictive capability of a two-dimensional finite element structural program by performing a simulation of the Project Salt Vault (PSV) experiment and comparing the numerically computed deformations to those which were measured during the PSV experiment. In addition to the prediction of deformations in PSV, an additional study was performed relative to the prediction of the temperature history which was measured during the PSV experiment (7). 


\section{DESCRIPTION OF PROJECT SALT VAULT}

\subsection{General Description and Objectives}

The Project Salt Vault experiment was designed and performed with four specific objectives ${ }^{(8)}$ :

(1) demonstrate waste handling methodology;

(2) determine effects of radiation on salt in regions of elevated temperature;

(3) determine the possibility of radiolytic production of chlorine;

(4) collect design related information on creep and plastic flow of salt at elevated temperature.

Project Salt Vault was performed in the Carey Salt Company mine at Lyons, Kansas. The area within the mine where the experimentation was performed was excavated on the western edge of the old workings at a depth of approximately 1,000 feet. The area was excavated at the end of a newly driven drift and was approximately 14 feet above the level of the old workings. Four rooms, which encoripasised the majority of the experimental area, were driven off the experimental area haulageway as shown in Figure. 2.1. A fifth room was also excavated as indicated in the figure for various special purpose experiments.

As shown in Figure 2.1, rooms 1 and 4 contained arrays of seven heat generating canisters located in the center of the rooms. The canister assemblies were nominally six feet in length and were emplaced in drillholes twelve feet deep. In the case of room 1, the heat generation was provided by a radioactive source which consisted of spent fuel assemblies from the Experimental Test Reactor facility near Idaho Falls, Idaho. The heat generation in room 4 was provided by electrical heaters.

Additional heat was provided to the PSV area by a series of 22 pillar heaters spaced on both sides of pillar 2-3. These heaters were nominally six feet in length and again emplaced in drillholes twelve feet in depth. Additional heat was supplied in this region through the use of a modified heater which was emplaced on the room 2 side of pillar 2-3. This heater operated at a higher power level and difierent period of time than the other 21 assemblies. 


\subsection{Instrumentation}

During the course of. Project salt Vault, four major specific types of instrumentation were employed, viz:

(1) Thermocouples in boreholes,

(2) Leveling pin stations,

(3) Extensometers,

(4) USBM stressmeters.

The utilization and placement of the thermocouples are discussed elsewhere ${ }^{(9)}$.

The leveling stations generally consisted of anchors emplaced and anchored nominally two feet into the salt. These stations were utilized directly for convergence measurements ( $i . e$. the relative movement between two stations), or as absolute displacement measurements. In the case of the absolute measurements, a level survey was performed from a reference position in the haulageway leading to. the PSV area (some 475 feet from the nearest heat source) to the level station being monitored. The accuracy of this type of measurement is stated as being repeatable within \pm .024 inches $^{(9)}$.

Wire extensometers were installed in all of the pillars separating the experimental rooms, in the barrier pillars, and in the west wall of each room (see Figure 2.2). In the case of the room pillars, the extensometers were anchored at the center of the pillars. Extensometers in the barrier pillars and room walls were anchored at a distance (40 to 50 feet) which was believed to be experiencing no deformation due to excavation or heating. The type of extensometer used in PSV can be expected to be accurate to 0.001 inches ${ }^{(9)}$.

The USBM stressmeters utilized in PSV were never calibrated in salt and as such, the meter readout was never related to a stress magnitude. The trend or transient response of the meters was, however of interest and seemed to indicate a general correlation between stress changes and meter readings.

\subsection{Chronology}

The chronology of mining excavation and heat transfer related events are tabulated in Table 2.1. The mining activity which was initiated in September, 1964, proceeded for approximately $6 \frac{1}{3}$ months. The array heaters 
were started on November 15, 1965 and operated at a nominal power level of $1.5 \mathrm{kw}$ per container for approximately one year at which time the pillar heaters were activated. This power was maintained for another two and one half months, at which time the array power was increased by $40 \%$. The array heater power was ierminated on June 14, 1967 (5 months after the power boost). The pillar heaters operated until October 9, 1967 at which time they were shut off.

Heat transfer events which are not displayed in Table 2.1 include the changing of fuel assemblies in room 1 in June, 1966 and November, 1966, the electrical heater failures in room 4 approximately 100 days after power initiation and the history of the modified heater installed in room 2 near pillar 2-3. In addition, none of the heat transfer events occurring in room 5 are presented. These events are described in detail in Reference (9). 


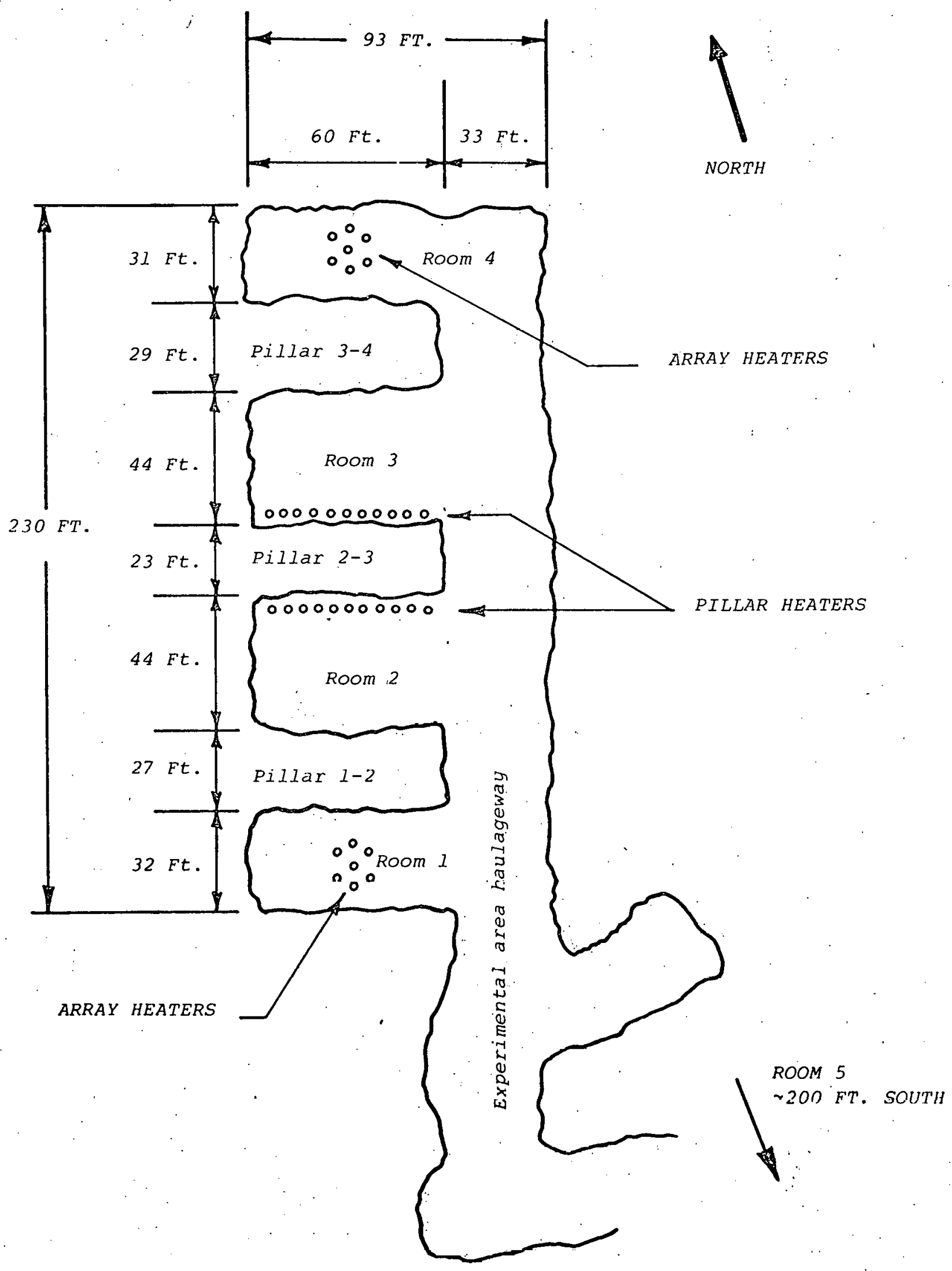

Figure 2.1. Plan of Project Salt Vault Experimental Area. 


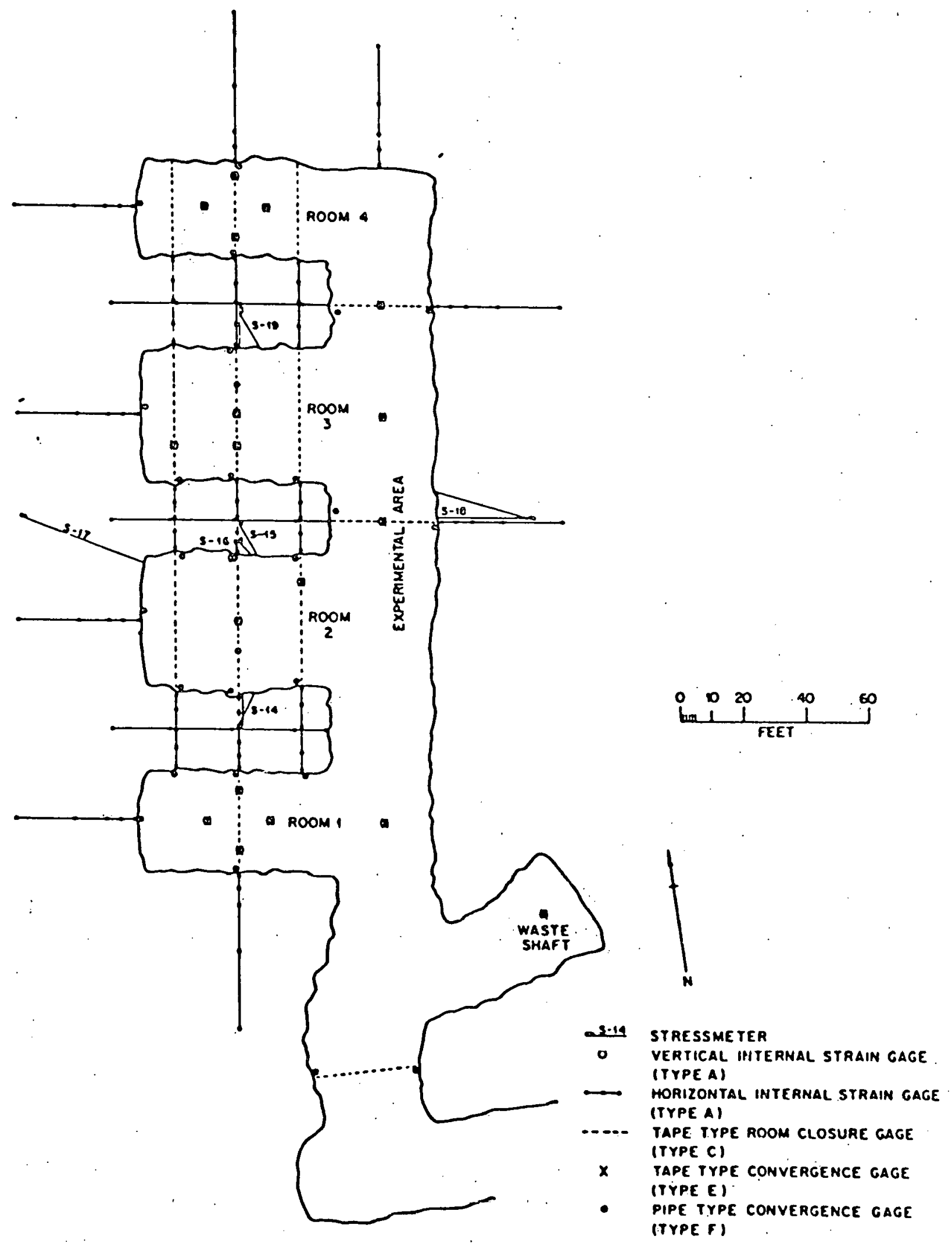

Figure 2.2. Rock Mechanics Instrumentation Plan for Project Salt Vault (After Bradshaw and MCClain, 1971). 
TABLE 2.1

CHRONOLOGY OF PROJECT SALT VAULT

\begin{tabular}{|c|c|c|}
\hline $\begin{array}{l}\text { Standard * } \\
\quad \text { Day }\end{array}$ & Date & Event \\
\hline$\sim 366$ & Sept. 2; 1964 & $\begin{array}{l}\text { Initiation of Experimental Area } \\
\text { Excavation }\end{array}$ \\
\hline$\sim 600$ & Mar. 25,1965 & $\begin{array}{l}\text { Completion of Experimental Area } \\
\text { Excavation }\end{array}$ \\
\hline 806 & Nov. 15,1965 & $\begin{array}{l}\text { Start of experiment; Array power } \\
\text { on }\end{array}$ \\
\hline 1170 & Nov. 14,1966 & Pillar heaters activated \\
\hline 2240 & Jan. 23,1967 & Array Power increased by $40 \%$ \\
\hline 1382 & June 14,1967 & Array Power terminated \\
\hline 1499 & Oct. 9, 1967 & Pillar heater power terminated \\
\hline
\end{tabular}

* Standard Day 1 was September 1, 1963 (9). 


\section{FINITE ELEMENT MODELING}

\subsection{Geometric Approximation}

The Project Salt Vault experiment was approximated with a twodimensional plane strain finite element model. Specifically, a vertical slice was taken on a north-south line from the barrier pillar/haulageway south of room 1 to the center of pillar 1-2. The horizontal width of the model was subsequently 192.5 feet. The total height of the model was 154 feet. Rooms $l$ and 2 were assumed to be nominally 32 feet and 44 feet wide, respectively, and 14 feet high. The actual dimensions of these rooms ${ }^{(9)}$ were within \pm 1.5 feet of the dimensions of the modeled rooms.

The bottom boundary of the model was restrained from vertical movement. Both vertical boundaries were restraineä from horizontal displacement. In the case of the right-hand vertical boundary (through the center of pillar 2-3), the boundary was restrained due to an assumption of symmetry. In actuality, this line is not a line of symmetry due to heating levels and the presence of old mine workings. However, for this study, the assumption was considered plausible. The left-hand vertical boundary was taken artibrarily to be horizontally constrained. specifically, the old workings were assumed to be far enough removed to provide negligible influence on the modeled experimental area. The implications of this assumption are discussed in further sections in this report.

\subsection{Chronology Approximation}

The chronology of the excavation and the heat transfer events as discussed in section 2.3 were not modeled exactly. As regards excavation, the mining sequence was not modeled, rather the rooms were assumed to be instantaneously excavated in a lithostatic medium. In this regard, a mean time period between excavation and activation of heating was utilized as 0.66 years. The chronology of mining and heat transfer events is displayed in Table 3.1.

Even though the study involving predictions of temperature histories for PSV (7) utilized the modeling of essentially. "individual" heaters for the array sources in room 1, this study utilized temperature histories from a lumped modeling. In other words, all heaters intersected by the model were represented with a single, equivalent heat generating. region. 
In this situation, three heaters were intersected by the model. Therefore, the heat generation in the model was equivalent to three times the heat generation of a single heater. Although this is not an exact representation, a comparison between the calculated and measured temperatures seems to justify this approximation. 


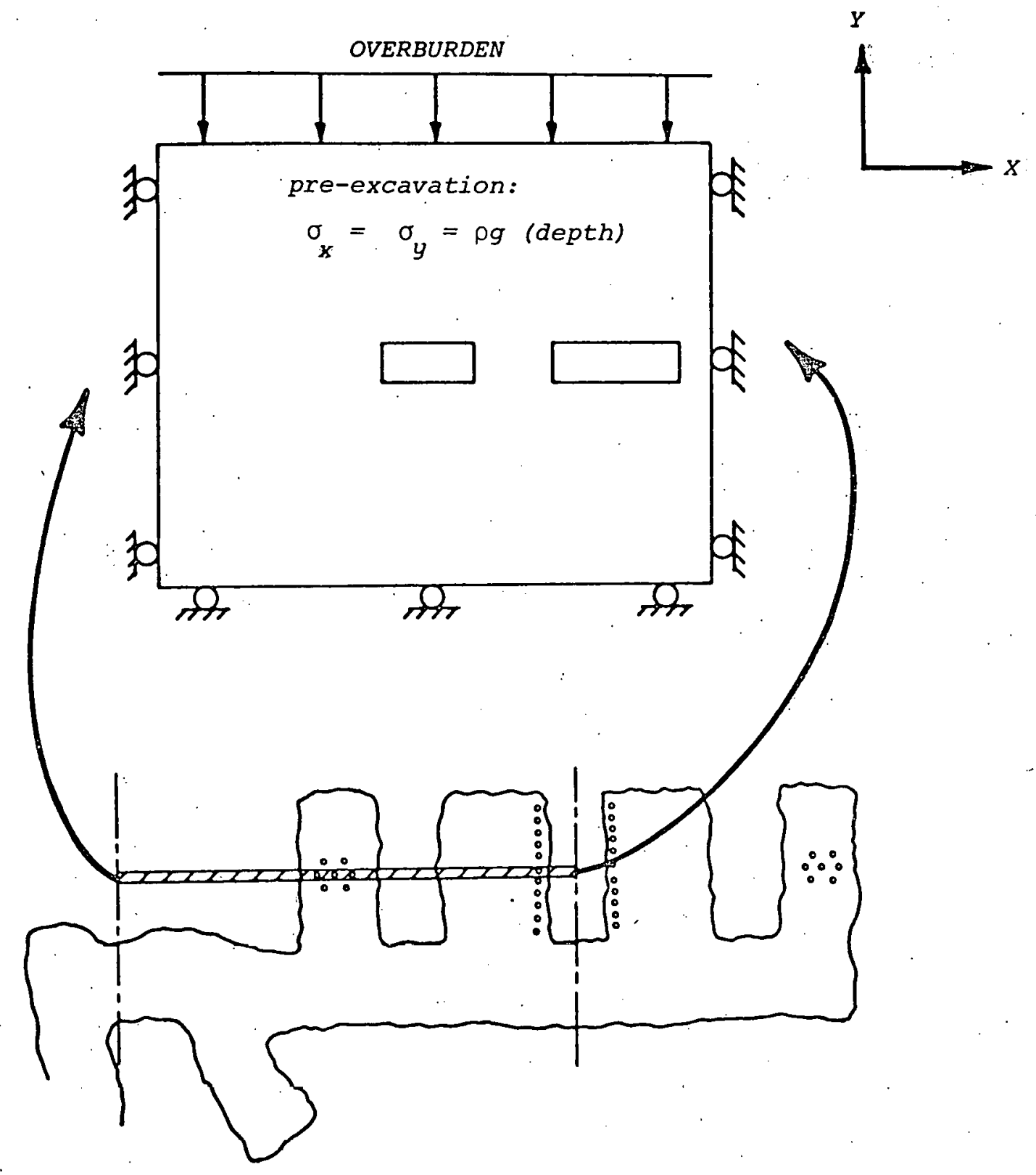

Figure 3.1. Simulation Model for the Project Salt Vault Experiment 
TABLE 3.1

CHRONOLOGY OF SIMULATED EVENTS

\begin{tabular}{|c|c|c|c|}
\hline $\begin{array}{l}\text { STANDARD } \\
\quad \text { DAY }\end{array}$ & $\begin{array}{c}\text { SIMULATION } \\
D A Y\end{array}$ & $\begin{array}{l}\text { EVENT LABEL } \\
\text { ON FIGURES }\end{array}$ & EVENT \\
\hline 555 & 0 & -- & $\begin{array}{l}\text { Excavation of Experimental Area } \\
\text { Completed }\end{array}$ \\
\hline - 806 & 241 & $A$ & Start of Experiment; Array Power On \\
\hline 1170 & 606 & B & Piliar Heaters Activated \\
\hline 1240 & 679 & c & Array Power Increased by $40 \%$ \\
\hline 1382 & 819 & $D$ & Array Power Terminated \\
\hline 1499 & 935 & $E$ & Pillar Heater Power Terminated \\
\hline
\end{tabular}




\subsection{Material Characterization}

For the purposes of the simulation of the Project salt Vault experiments, the model discussed in section 3.2 was assumed to be homogeneous salt. Investigations during PSV indicated shale stringers and shale seams in the area of the experiment $(9)$. However, the individual seams were not modeled and the characterization of the salt itself was. assumed to adequately represent the composite response of the salt mass with minor shale stringers and impurities.

The salt was taken to be viscoelastic and it was assumed that the constltutive law could be adequately represented as

$$
\varepsilon_{i j}=f\left(s_{i j}, t, T\right)
$$

where

$$
\begin{aligned}
\varepsilon_{i j} & =\text { strain rate tensor } \\
s_{i j} & =\text { deviatoric stress tensor } \\
t & =\text { time } \\
T & =\text { temperature }
\end{aligned}
$$

Numerous salt pillar model experiments had been performed at the Oak Ridge National Laboratory during and after the PSV period ${ }^{(9)}$. The data generated during these experiments were then fit to an equation of the form of [1]. Subsequent tests on two-inch diameter salt core from the mine were performed by RE/SPEC InC. (10). in support of the finite element simulation. The combination of the data from both References (9) and (10) resulted in the constitutive law:

$$
\varepsilon_{i j}=A\left(T / T_{0}\right)^{p} t^{m}\left(3 J_{2}\right)^{(n-1) / 2}\left(3 / 2 S_{i j}\right)
$$

where:

$$
\begin{aligned}
A & =\text { constant }=1.53\left(10^{-15}\right) \\
J_{2} & =\text { second invariant of the stress deviator } \\
t & =\text { time (seconds) } \\
T & =\text { temperature in degrees Kelvin } \\
T_{0} & =295.5^{\circ} \mathrm{K} \\
n & =3.0 \\
m & =0.4 \\
p & =9.5
\end{aligned}
$$


The additional thermal and mechanical material properties utilized in the simulation are presented in Table 3.2. These properties were taken from References (10) and (11).

As regards material characterization, two particular points of interest need be noted. Firstly, the constitutive law [2] or creep law utilized is an empirical relationship which includes variables (time) which are not internal system variables. Therefore, the law is not universally applicable. The law only empirically represents transient creep and neglects any secondary or tertiary creep. However, as will be discussed later, the gross salt creep which occurred during PSV was, in fact, transient and never appeared to enter the secondary. or steady state region. Secondly, the constitutive law [2] does not consider plastic deformation. The implication of this assumption will be discussed qualitatively in later sections of this report. 
TABLE 3.2

THERMAL AVD MECHANICAL PROPERTIES UTILTZED IN PSV SIMULATION

\begin{tabular}{|c|c|c|c|c|c|c|c|}
\hline $\begin{array}{l}\text { MATERIAL/ } \\
\text { LOCATION }\end{array}$ & $\begin{array}{c}E \\
(p s+1)\end{array}$ & $v$ & $\begin{array}{c}\rho \\
(p \subset f)\end{array}$ & $\begin{array}{c}\alpha \\
\left(\text { in./in. }-{ }^{\circ} F\right)\end{array}$ & 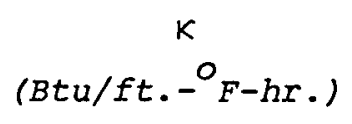 & $\begin{array}{c}c \\
\left(B t u / 1 b:-{ }^{o} F\right)\end{array}$ & $\left(B t u / f t .^{2}-{ }^{\circ} F-h r.\right)$ \\
\hline salt & $0.85\left(20^{6}\right)$ & 0.4 & 138 & $2.2\left(10^{-5}\right)$ & 2.5 & 0.22 & $\cdot$ \\
\hline $\begin{array}{l}\text { Heater } \\
\text { Region }\end{array}$ & $0.85\left(10^{6}\right)$ & 0.4 & 138 & $2.2\left(10^{-5}\right)$ & 2.5 & 0.22 & -- \\
\hline $\begin{array}{l}\text { Room } \\
\quad \text { Periphery }\end{array}$ & -- & - & - & - & - & -- & 1.0 \\
\hline
\end{tabular}




\section{COMPARISON OF FINITE ELEMENT AND PROJECT SALT VAULT RESULTS}

\subsection{Description of Finite Element Models}

Three distinct finite element models were utilized in the Profect Salt vault simulation. The specific features of the individual models are presented in Table 4.1 and the models are illustrated in Figures 4.14.3.

Model MI was designed to account for the individual array heaters as well as possible with a two-dimensional model, and to simulate only thermoelastic response. Additionally, this model was intentionally "well discretized" in the regions around the floox in an effort to assess the influence of floor stiffness. The applicability of this model will be discussed in further sections of this report.

All numerical approximation methods inherently result in elements, cells or regions which are stiffer than the physical medium being modeled until the element, cell or region is of a sufficiently small size as to represent the deformation of the medium with its numerical function. In theory, the finite element method approaches an exact representation of a medium as the size of an element approaches zero, or equivalently, as the number of elements approaches infinity. However, a practical approximation of a medium does not require an infinite number of elements (12). As regards element size and number of elements, it should be noted that Model MI is more flexible than Models M2 or M3 described below.

The salt in Model M2 was assumed to be thermo/viscoelast1c. This model did not incorporate the detail of individual array heaters; rather, the array heaters were "Iunped" into a single heat generating region.

Model M3 also assumed thermo/viscoelastic material characterization and had the identical heat generation distribution as employed in Model M2. Model $M 3$ differs from Model $M 2$ in that more finite elements are provided in regions of estimated high stress magnitudes and gradients resulting in a more "flexible" model. 
TABLE 4.1

FEATURES OF FINITE ELEMENT MODELS USED IN PSV SIMULATION

\begin{tabular}{|c|c|c|c|c|c|}
\hline MODEL & $\begin{array}{c}\text { HEIGHT } \\
(F T .)\end{array}$ & $\begin{array}{c}\text { WIDTH } \\
(F T .)\end{array}$ & $\begin{array}{c}\text { NUMBER } \\
\text { OF NODES }\end{array}$ & $\begin{array}{c}\text { DEPTH TO } \\
\text { NUMBER. } \\
\text { OF ELEMENTS }\end{array}$ & $\begin{array}{c}\text { ROOM FLOOR } \\
(F T .)\end{array}$ \\
\hline M1 & 304 & 192.5 & 974 & 304 & 1,000 \\
M2 & 154 & 192.5 & 333 & 92 & 1,000 \\
M3 & 154 & 192.5 & 480 & 133 & 1,000 \\
\hline
\end{tabular}




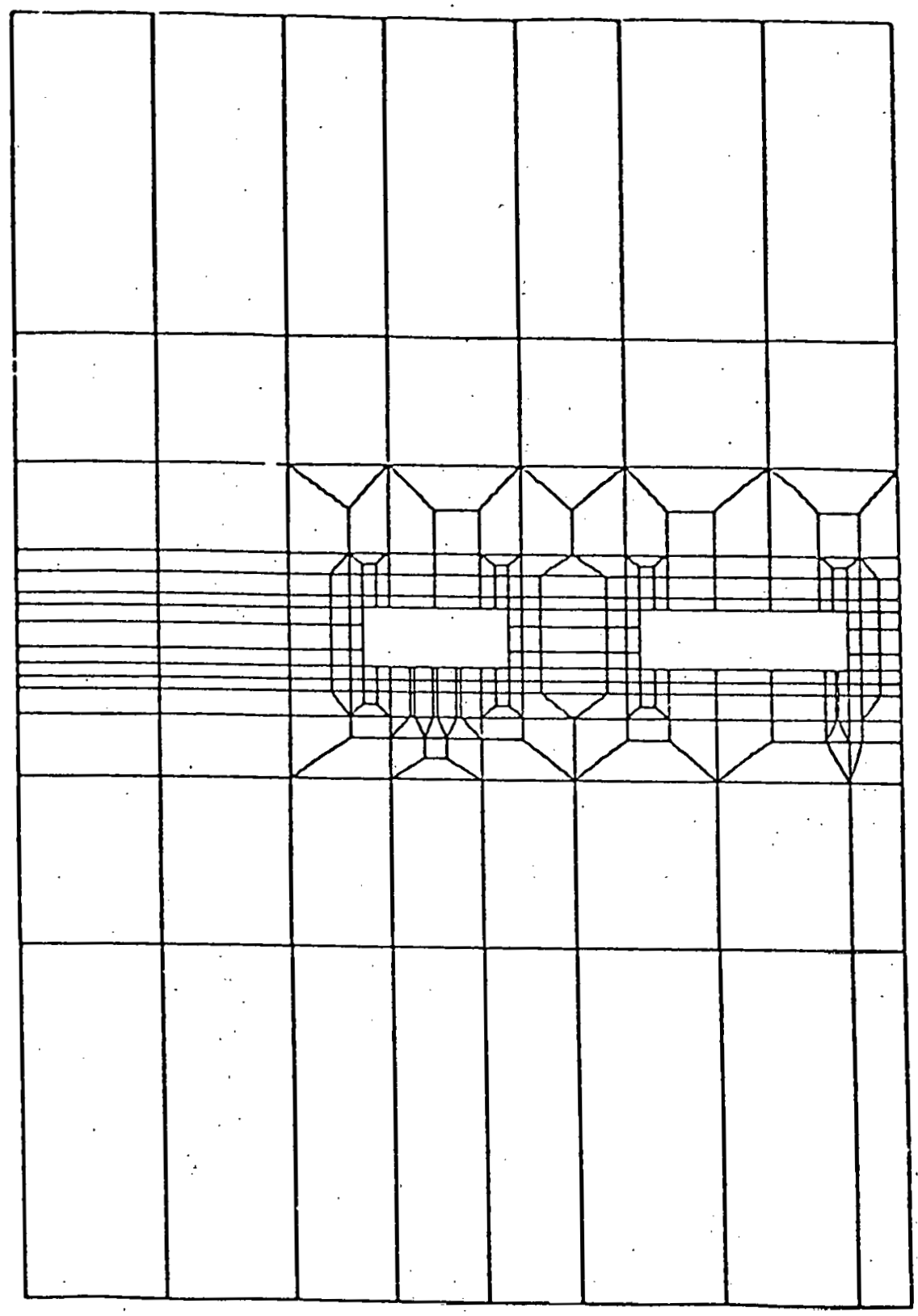

Figure 4.1. Finite Element Mesh M1. 


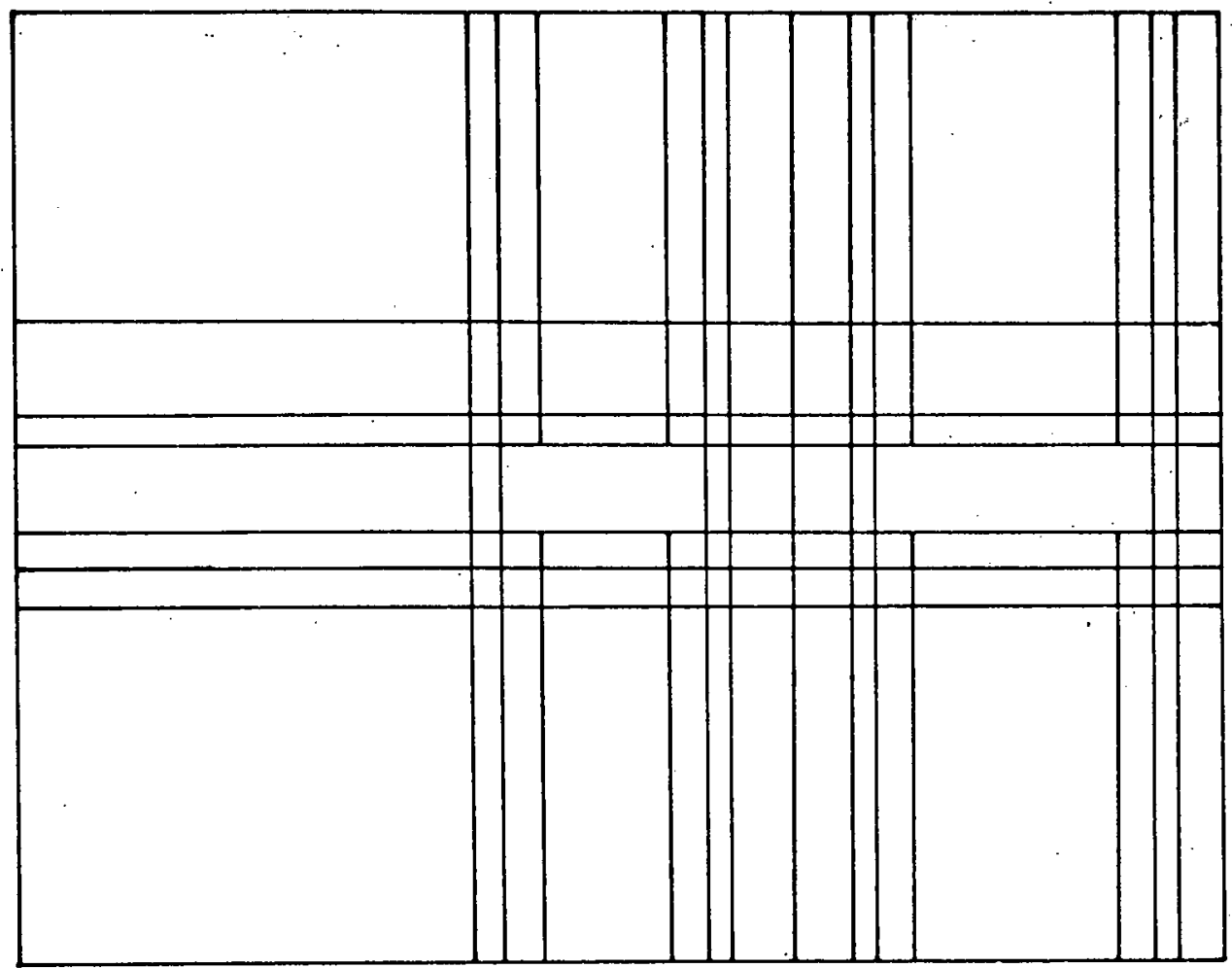

Figure 4.2. Finite Element Mesh M2.

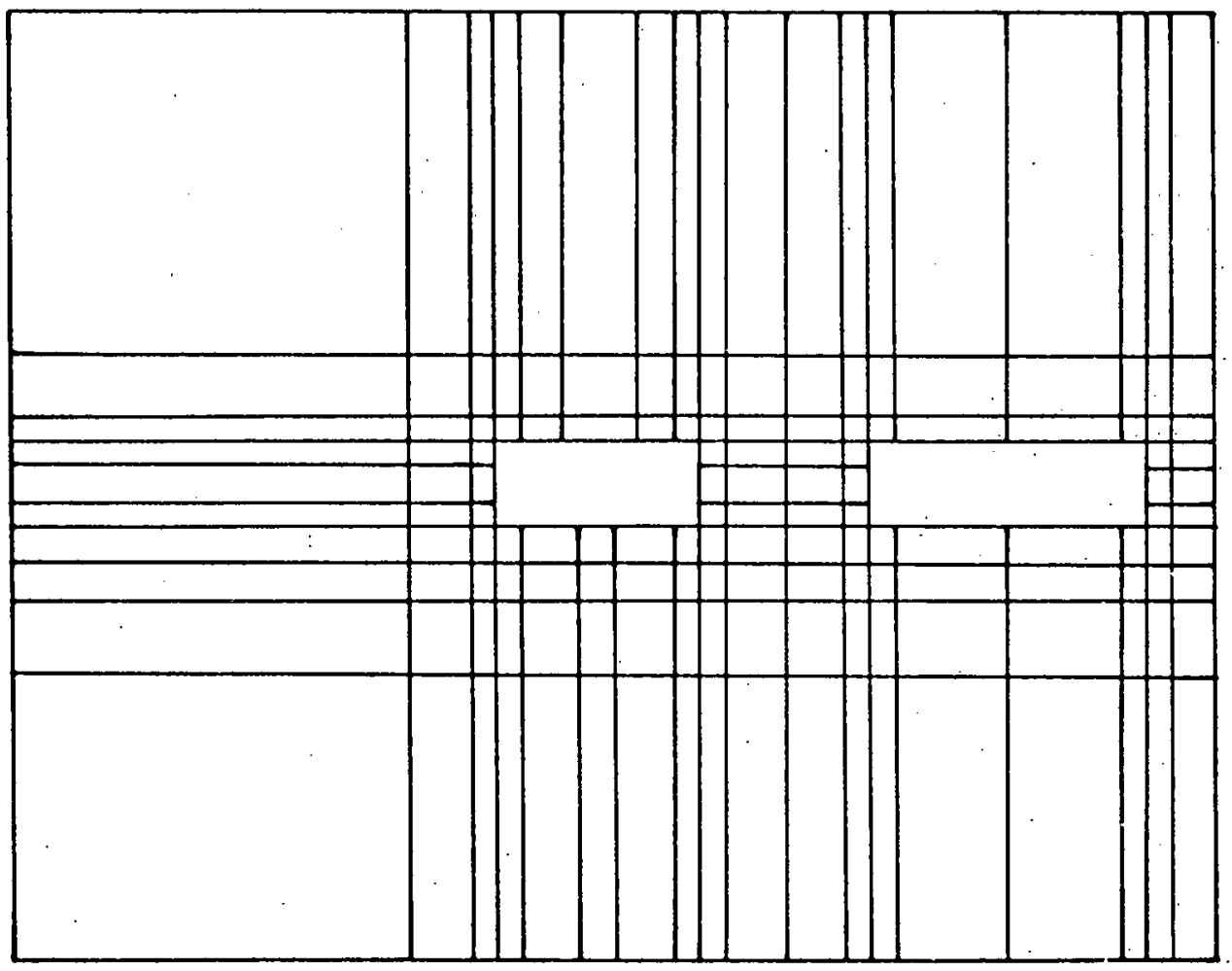

Figure 4.3. Finite Element Mesh M3. 


\subsection{Room Convergence Prior to Heat Initiation}

Prior to the instaliation and powering of the various heat generating assemblies, room convergence measurements were performed in both rooms 1 and 4 near the rib of the respective barrier pillars and near the rib directly opposite the barrier pillars. These convergence measurements were subsequently utilized to obtain measured convergence rates. The measured convergence rates for the two rooms are presented in Figure 4.4 as a function of time, together with the calculated convergence rates obtained from Models $M 2$ and $M 3$.

Two observations of the PSV aata in Figure 4.4 merit discussion. First, the measured convergence rates and the deceleration of convergence for rooms 1 . and 4 are not identical. Therefore, the conclusion can be made that the PSV area was not symmetric about the center of Pillar 2-3 with respect to convergence. After the rooms have been open for 100 days, the convergence rate in Room 1 is approximately twice that of room 4; and after 200 days, the ratio of the convergence rates has reduced to approximately 1.6 .

A second observation of importance regarding the experimental measurements is that no steady state creep is apparent. specifically, if steady state creep were present, the convergence rate would be constant with time.

The deceleration of the convergence in Models $M 2$ and M.3 agree better with room 4 than with room 1 . However, the magnitude of the convergence rate in the two models is approximately the mean of the two PSV rooms.

\subsection{Roum Convergence After Heat Initiation}

Throughout the remainder of this report; PSV experiment data will be displayed with curves which contain symbols. The PSV data has been taken from Reference (9) and a tabulation of the Reference (9) figure number utilized in each of the figures in this report is provided in the Appendix. Two different time scales are provided in the figures of this report when transient events are displayed. Specifically, PSV standard days ${ }^{(9)}$ and finite element simulation days are utilized. The events identified as $A, B, C, D$ and $E$ are described in Table 3.1. Whenever possible, simulation results for room 1 are compared to PSV data from both rooms 1 and 4. Similarly, simulation results for room 2 are compared to PSV data from rooms 2 and 3. 
Figure 4.5 displays the transient vertical convergence in the center of room 1 of Models $M 2$ and $M 3$ and the PSV measured convergence in the center of rooms 1 and 4. The convergence in the simulation models after heating initiation is not as great as that which was measured in PSV. Additionally, the deformation in the simulation models was not all permanent as appears to be the case with the field convergence. The reason for the inconsistency can be hypothesized to be related to several phenomena. Firstly, the convergence measurement locations (shown in Figure 4.5) were in the vicinity of a flexible roof region. specifically, these convergence measurements were near the experimental haulageway. The two-dimensional simulation model assumes that no haulageway exists. Secondly, the permanent deformation indicated in the PSV results may be due to a salt separation along the shale: stringers or seams in the roof and floor of the experimental area. This would account for not only the irreversibility of the convergence, but also the magnitude of the convergence.

Figure 4.6 compares the vertical transient convergence in the center of room 2 for both thermo/viscoelastic models with that measured in PSV rooms 2 and 3. As was the case with rooms 1 and 4, the simulation results do not illustrate the same magnitude of convergence as the measured results. However, it is encouraging to note that the convergence rate in the models prior to activation of the pillar heaters agrees well with that which is indicated by the measurements. It should also be noted that the convergence in the models appear to be permanent. These convergence stations were not in a region of high thermal loaling and this may account for the lack of reversible deformation. The reversible deformation in room 1 of the simulation models is mainly due to the "unloading" occurring due to the termination of heating. The discrepancy in the modeled and measured magnitude of convergence in the center of room 2 is probably related to the phenomena discussed for room 1 . The transient vertical convergence in room 1 near pillar 1-2 of the simulation models is compared to the measured convergence in room 1 near pillar 1-2 and in room 4 near pillar 3-4 in Figures 4.7 and 4.8, respectively. Due to the fact that the model represented instantaneous excavation, the model convergence begins after the actual convergence in room 1 and before the actual convergence in room 4 (see mining sequence rable 2.1). The model results follow the convergence in room 1 well, 
until after the $40 \%$ array power boost (event $C$ ). Once again the models do not reflect the apparent permanent deformation exhibited in the PSV results.

Figures 4.6 and 4.7 compare the vertical convergence in room 2 near pillar 2-3 with the PSV measured convergence in room 2 near pillar 2-3 and in room 3 near pillar 2-3, respectively. As was the case with the comparison in the center of room 2 , the convergence rates of the models agree well with those exhibited in the PSV results prior to activation of the pillar heaters. The magnitude of the model convergence is comparable to that measured in the PSV experiment; however, the PSV measurements do not reflect the convergence occurring between mining and initiation of convergence measurements. 


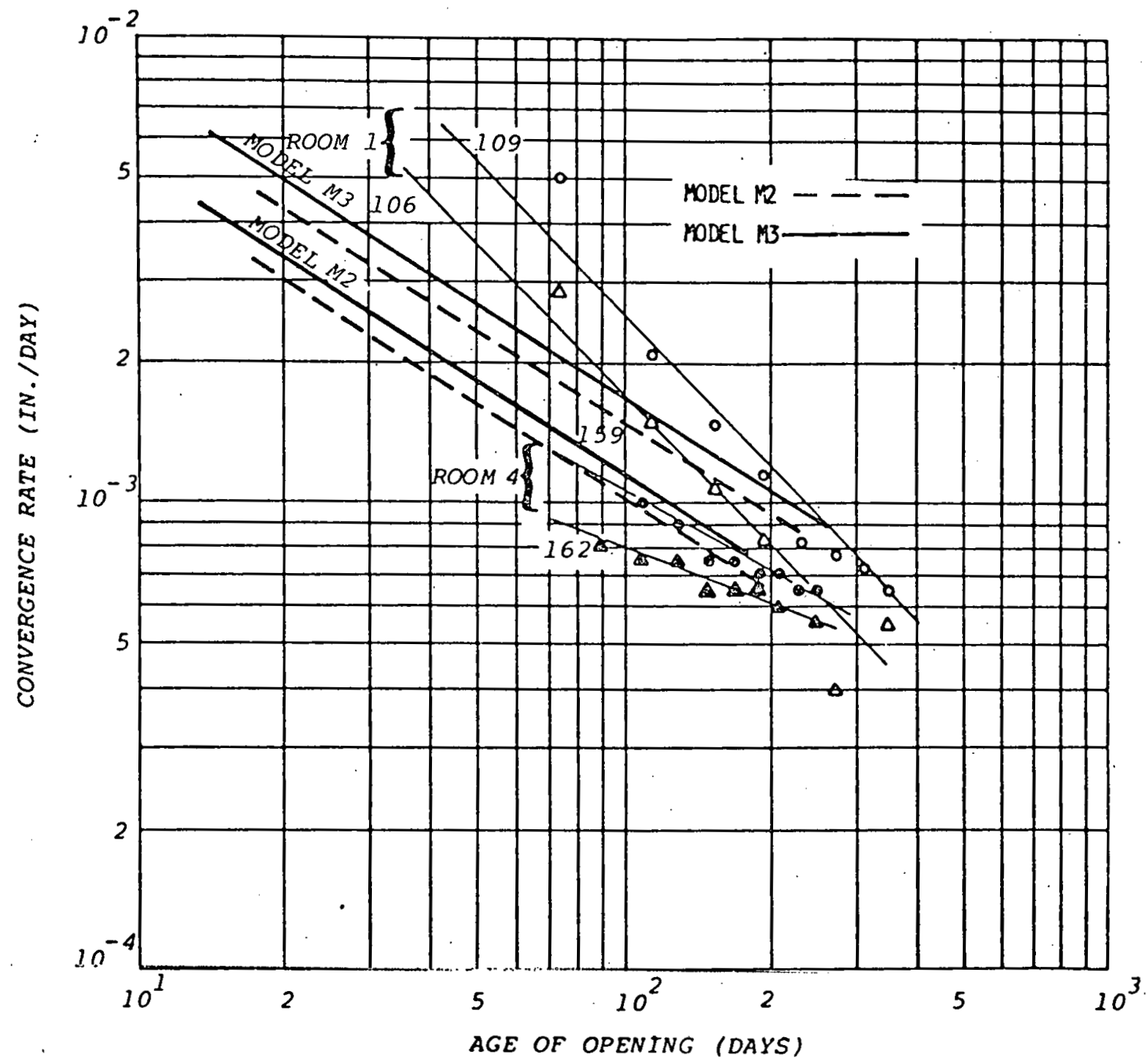

LEGEND.

O. Convergence Station 109;

South Rib of Pillar 1-2

$\Delta \quad$ Convergence Station 106;

North Rib of Barrier Pillar for Room 1

- Convergence Station 159;

North Rib of Pillar 3-4

A Convergence Station 162;

South Rib of Barrier Pillar for Room 4

Figure 4.4. Vertical Convergence Rate as a Function- of Time for Rooms 1 and 4 (Prior to Heating). 


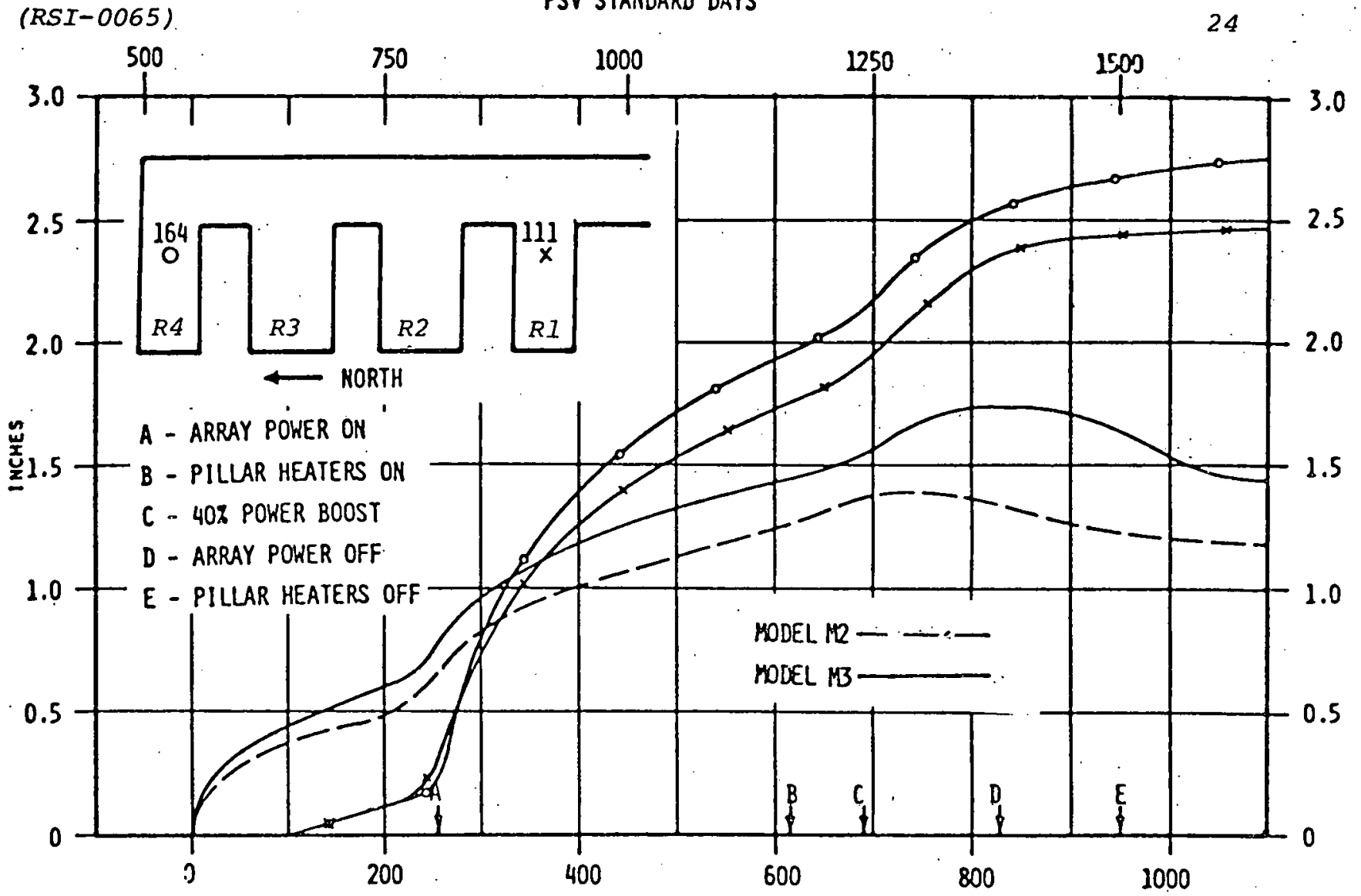

SIMULATION DAYS.

Figure 4.5. Vertical Convergence in the Center of Rooms 1 and 4. PSV STANDARD DAYS

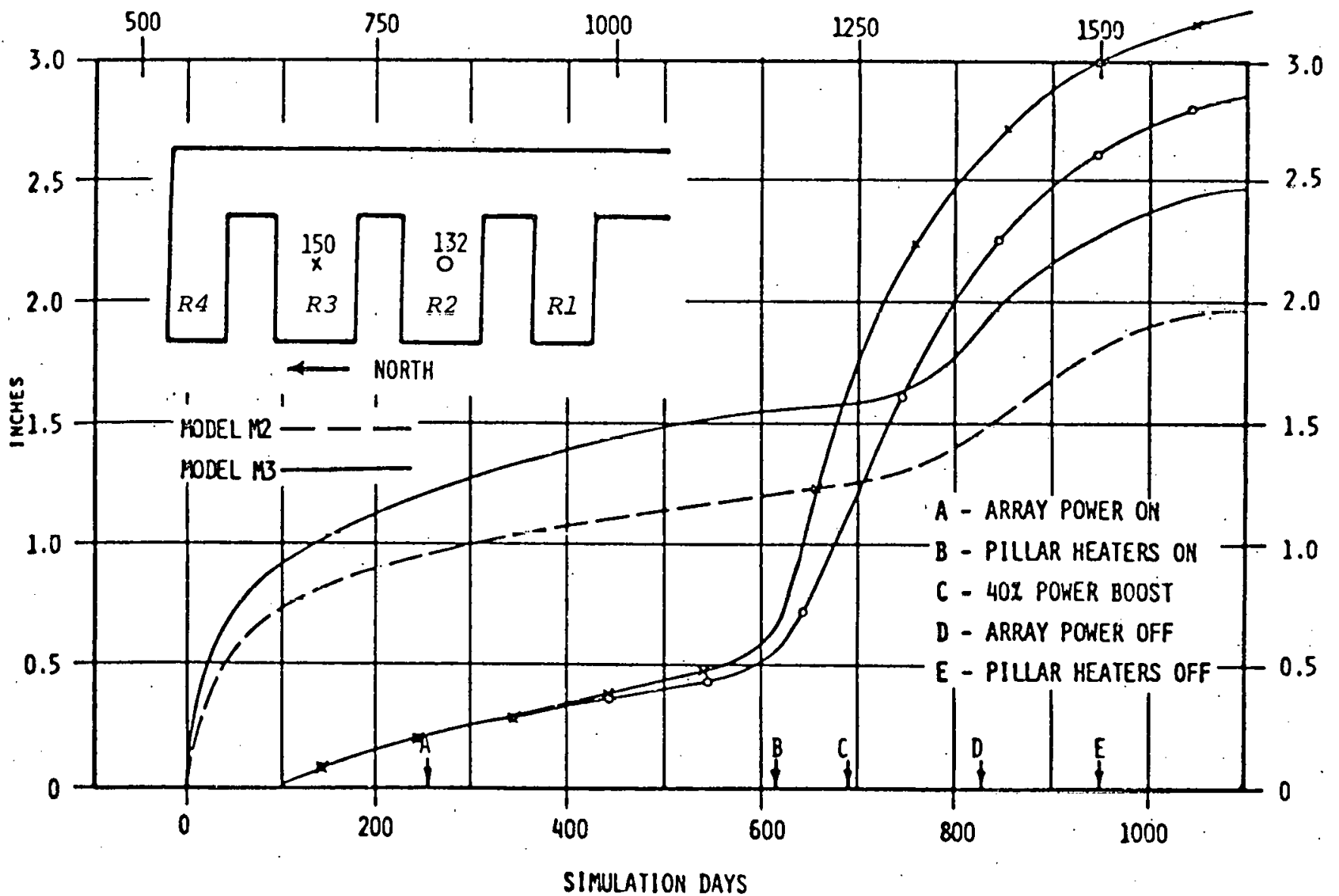

Figure 4.6. Vertical Convergence in the Center of Rooms 2 and 3. 


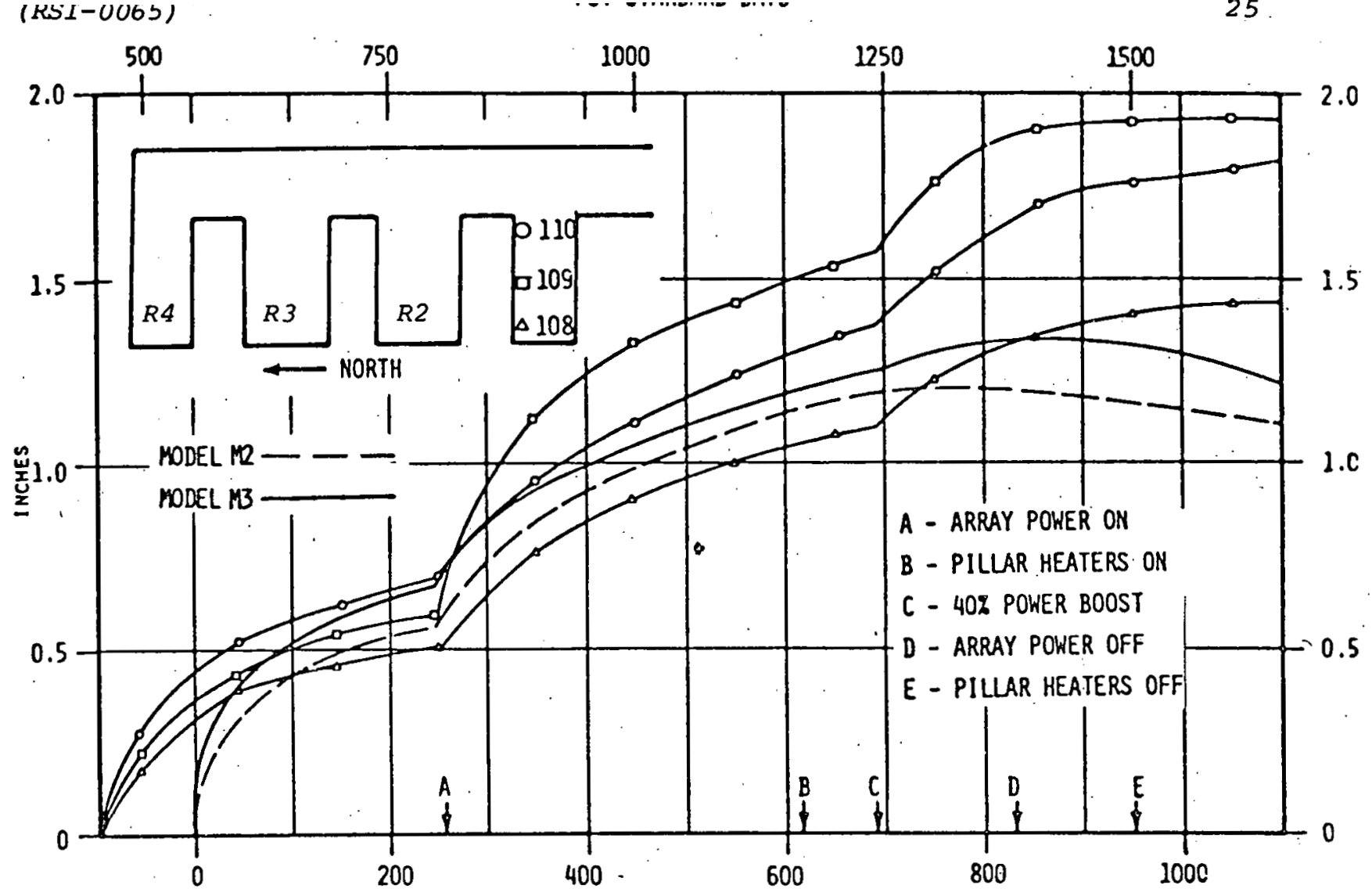

SIMULATION DAYS

Figure 4.7. Vertical Convergence in Room 1 Near Pillar i-2.

PSV STANDARD DAYS

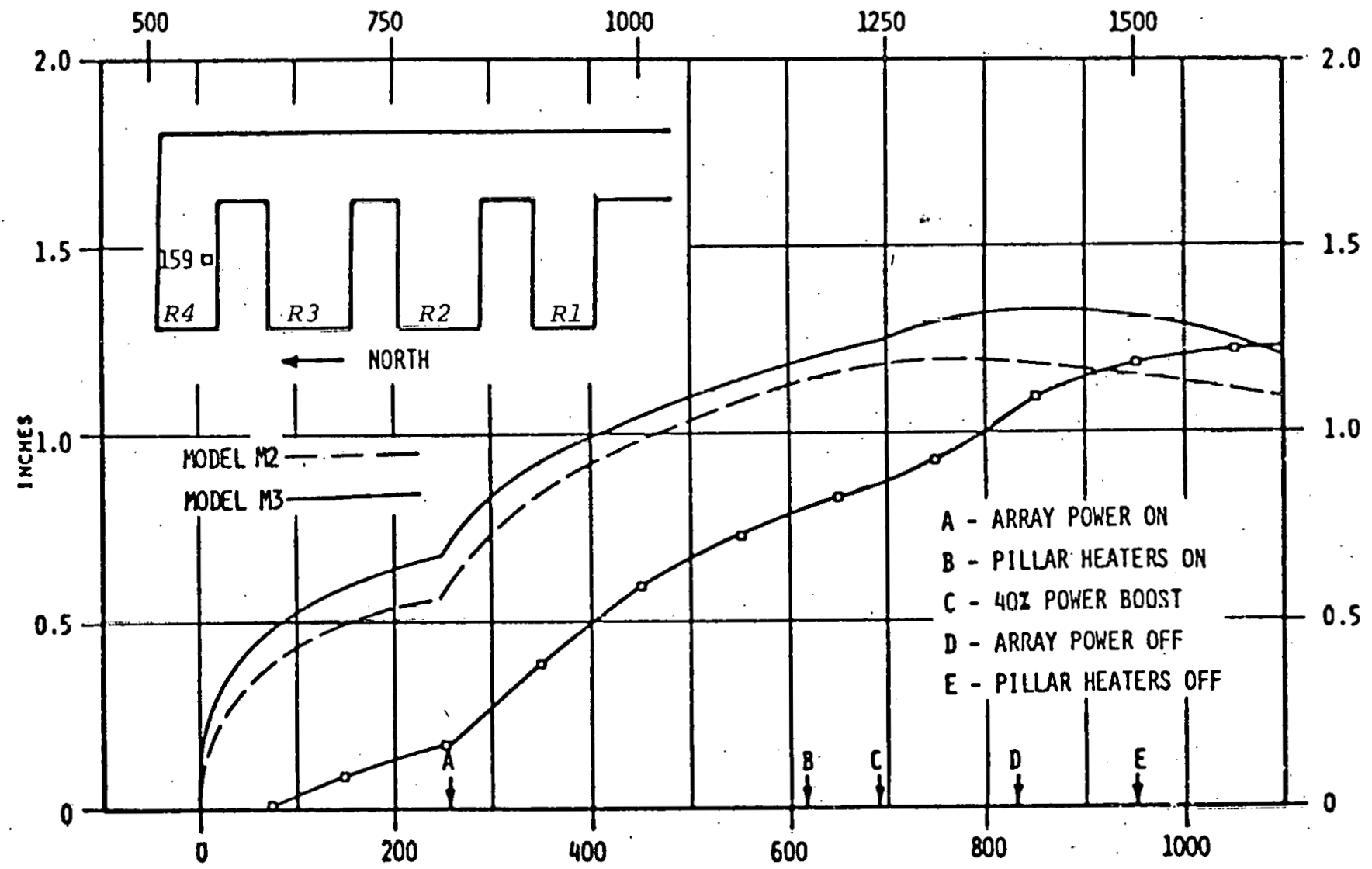

SIMULATION DAYS

Figure 4.8. Vertical Convergence in Room 4 Near Pillar 3-4. 
(RSI-0065)

PSY STANDARD DAYS

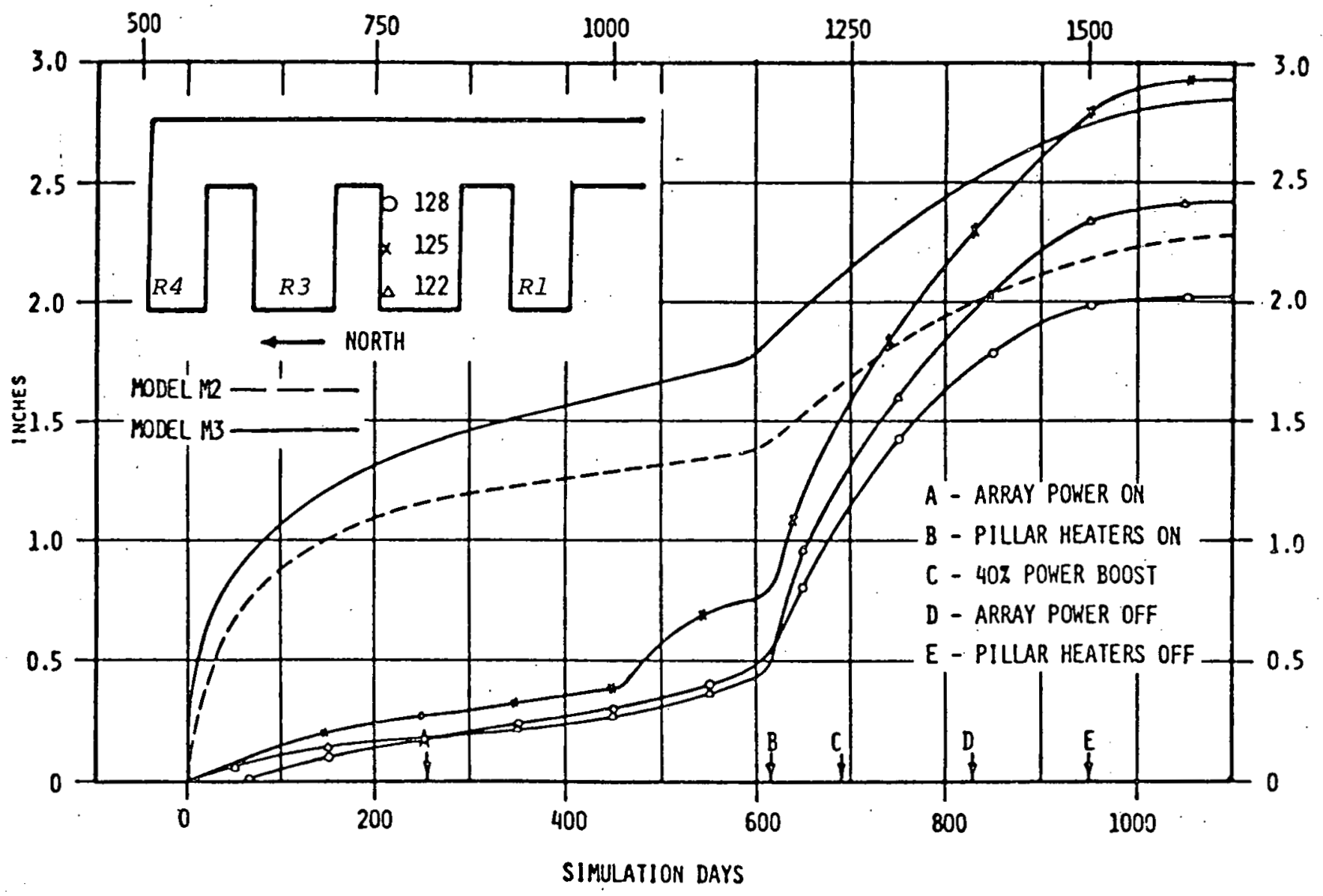

Figure 4.9. Vertical Convergence in Room 2 Near Pillar 2-3. PSV STANDARD DAYS

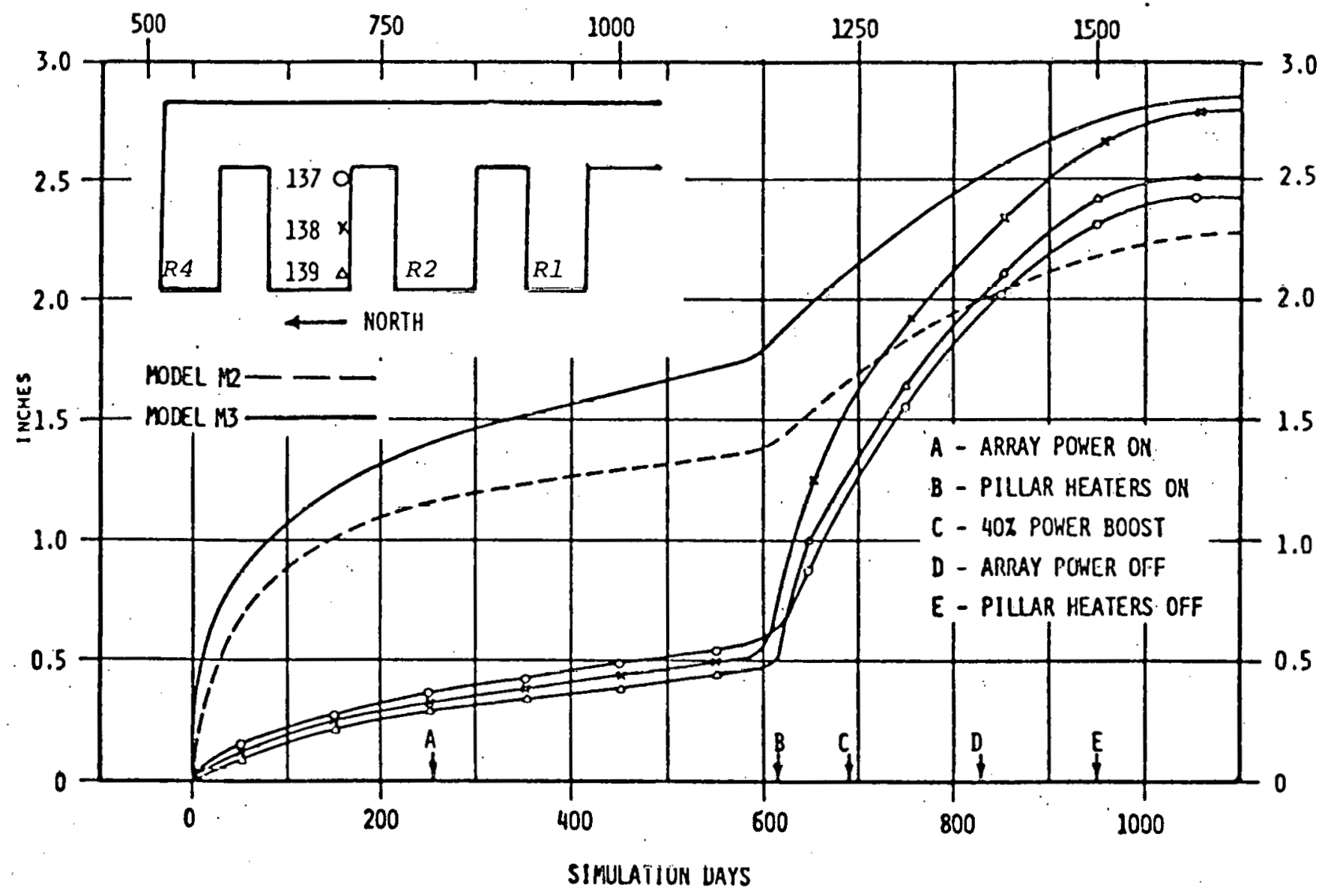

Figure 4.10. Vertical Convergence in Room 3 Near Pillar 2-3. 


\subsection{Floor Uplift}

In this section of the report, results from all three finite element models will be compared to the Project salt Vault experimental results. As stated previously, Model $M I$ was intentionally designed with a large number of degrees of freedom in the floor region in both rooms 1 and 2 in order to obtain a model that would provide a flexible response to the thermoelastic loading in the floor.

The PSV transient floor uplift data from rooms 1 and 4 are compared to the results from each of the models in Figures 4.11 and 4.12, respectively. As can be observed in the figures, the thermoviscoelastic models (M2 and M3) do not exhibit uplifts of the magnitude of the measured PSV uplifts. Additionally, not all of the permanent deformation apparently exhibited in the measured uplift is apparent in the results of Models M2 and M3. The thermoelastic results of Model M1 show a greater magnitude of uplift than the PSV results, and obviously, no permanent deformation is possible in this model. Since the thermoelastic model does not allow for stress relaxation (either viscous or plastic) it is not surprising that the magnitude of the uplift is greater than that which was measured. In this regard, the thermoelastic model can be thought of as an upper bound.

The transient floor uplift in the center of rooms 2 and 3 is illustrated in Figure 4.13. None of the models display the total magnitude of the measured results. However, the rate of uplift for each of the models is generally in agreement with the PSV results.

The profiles of floor uplift at selected times along a line parallel to the experimental haulageway for rooms 1 and 4 are illustrated and coimpared to each of the models in Figures 4.14 through 4.19. As was the case with the transient floor uplift, Model Ml exhibits more upiift than the PSV measured results and Models $M 2$ and $M 3$ exhibit less uplift. It is of interest to note that the thermoelastic model (MI) exhibits more uplift in the corners of the rooms than is present in the measured results. This is probably due to the fact that no stress relaxation is allowed in the model, which would result in less uplift.

The PSV floor uplift profiles in rooms 2 and 3 across the heated pillar at several locations are illustrated and compared to each of the modcls in Figures 4.20 through 4.28. It is at this location where the two dimensional model is most realistic ${ }^{(7)}$ and as can be observed in the figures, the 
agreement for each of the models is quite good. However, at the midsection of the pillar, none of the models provide good agreement with the measured results due to the fact that the. large amount of floor uplift at this location is due to the presence of the modified pillar heater ${ }^{(9)}$. 


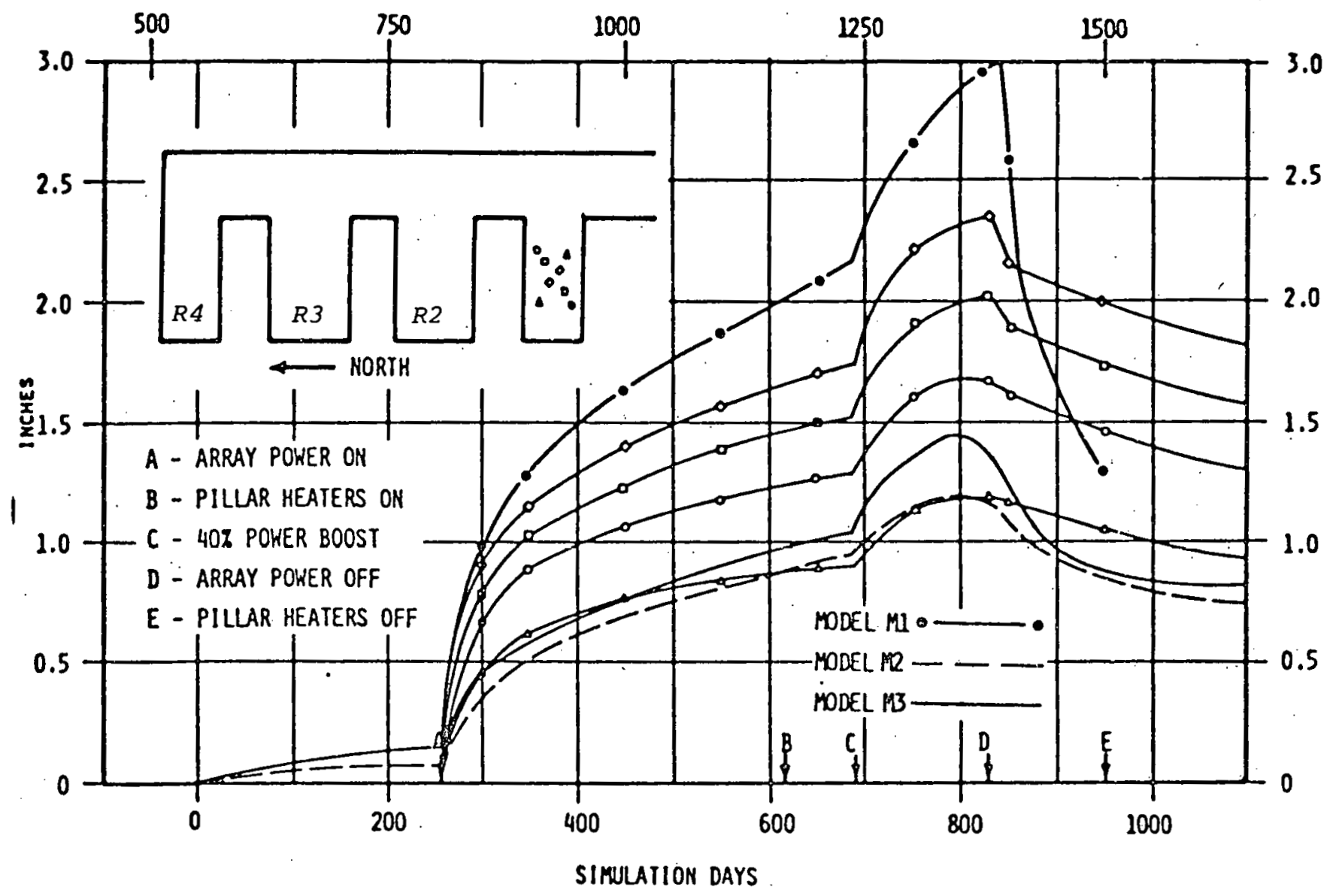

Figure 4.11. Transient Floor Uplift in Room 1 .

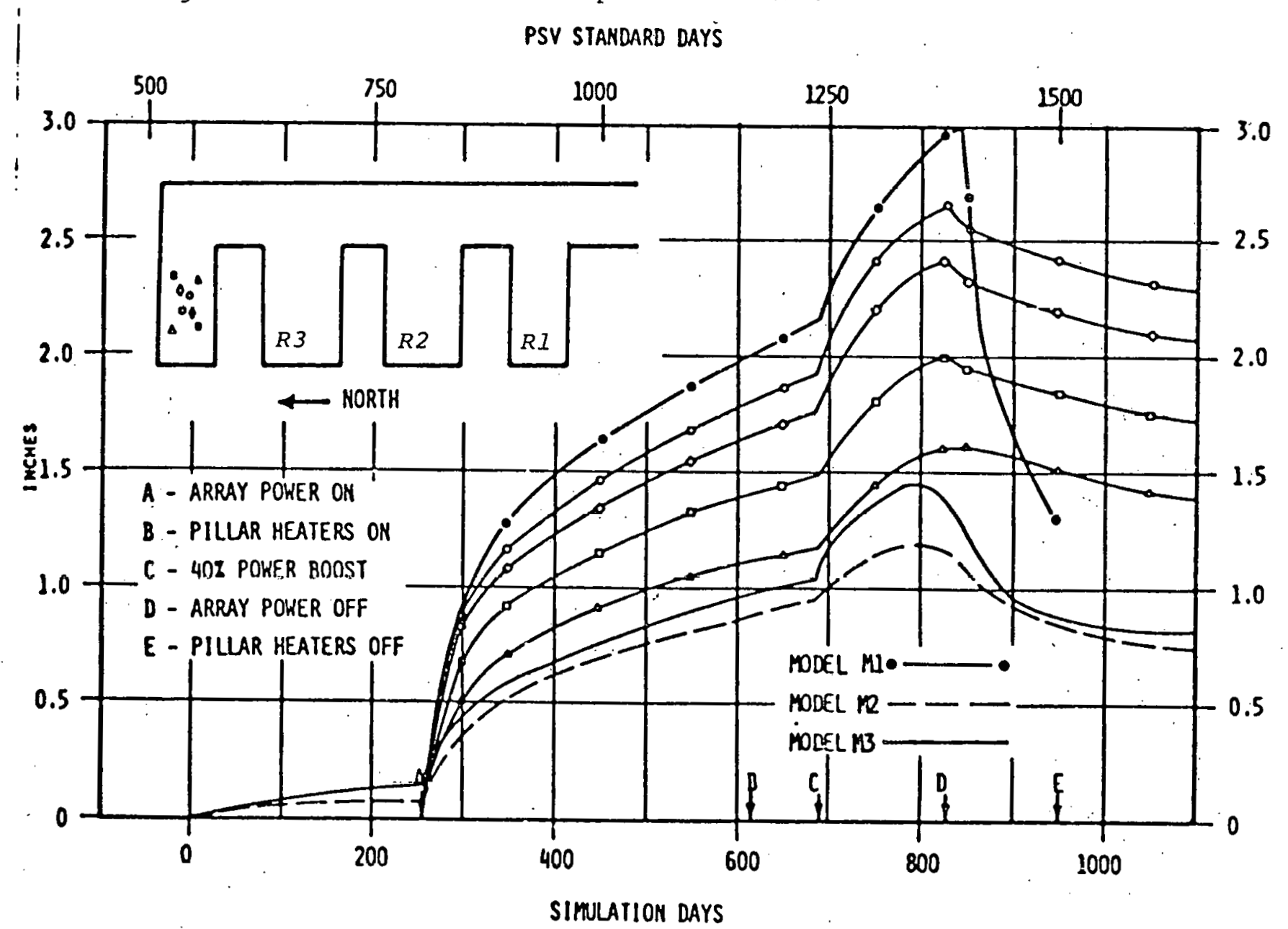

Figure 4.12. Transient Floor Uplift in Room 4. 


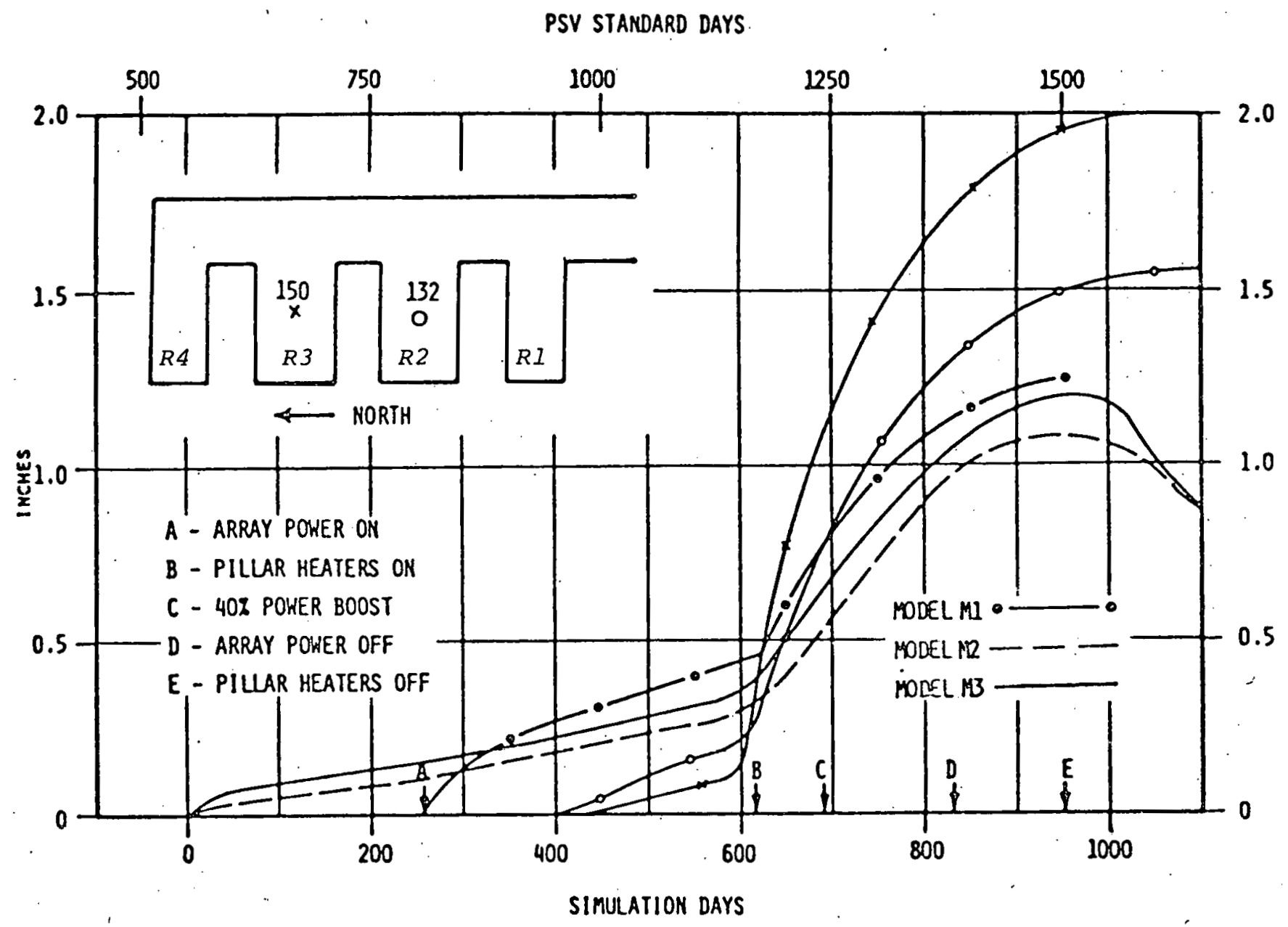

Figure 4.13. Transient Floor Uplift in Rooms 2 and 3. 


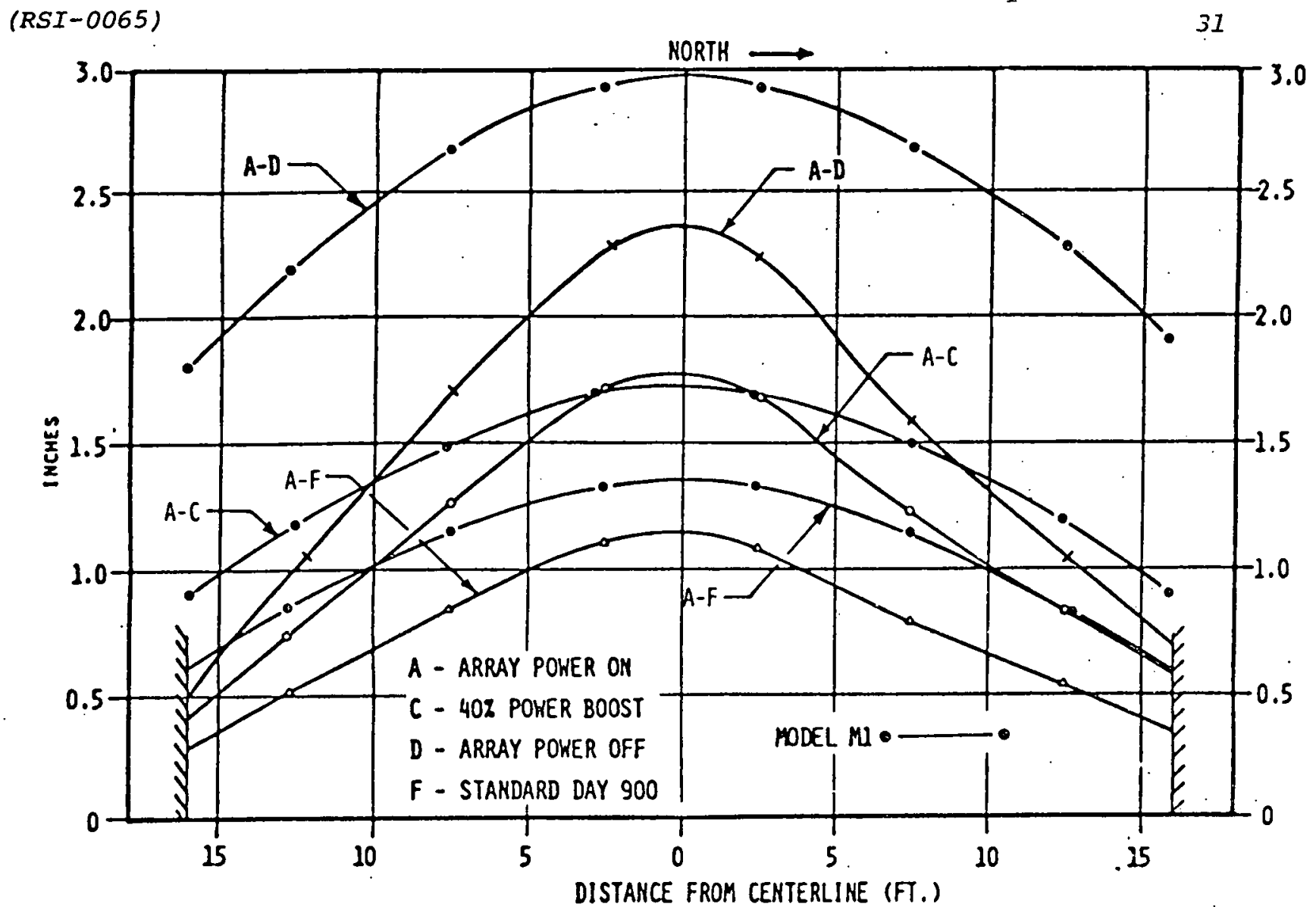

Figure 4.14. Floor Uplift Profiles at Selected Times; Model M1-Room 1.

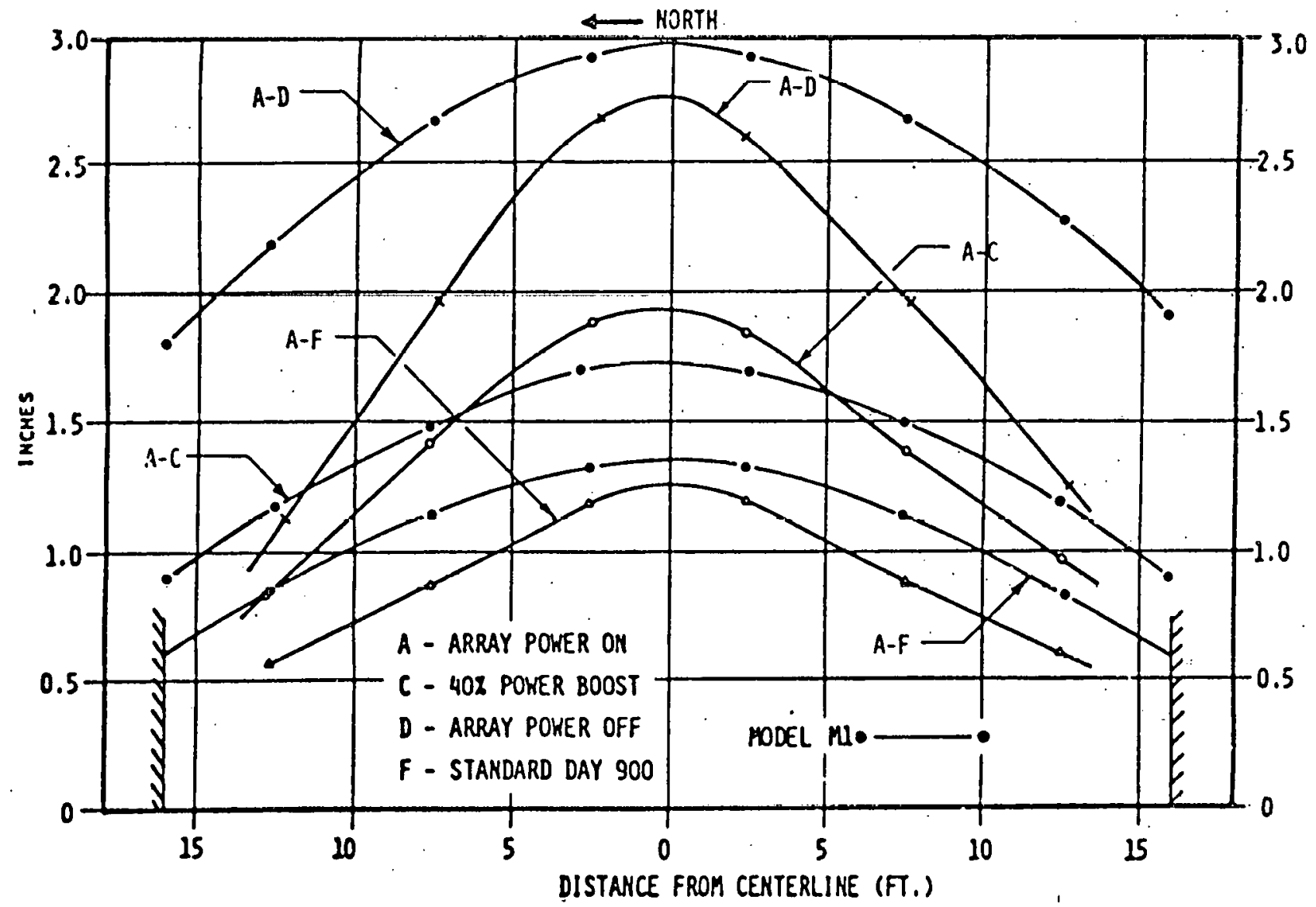

Figure 4.15. Floor Uplift Profiles at Selected Times; Model M1-Room 4. 
$(R S I-0065) . \quad$ NORTH $\underset{\longrightarrow}{\longrightarrow}$

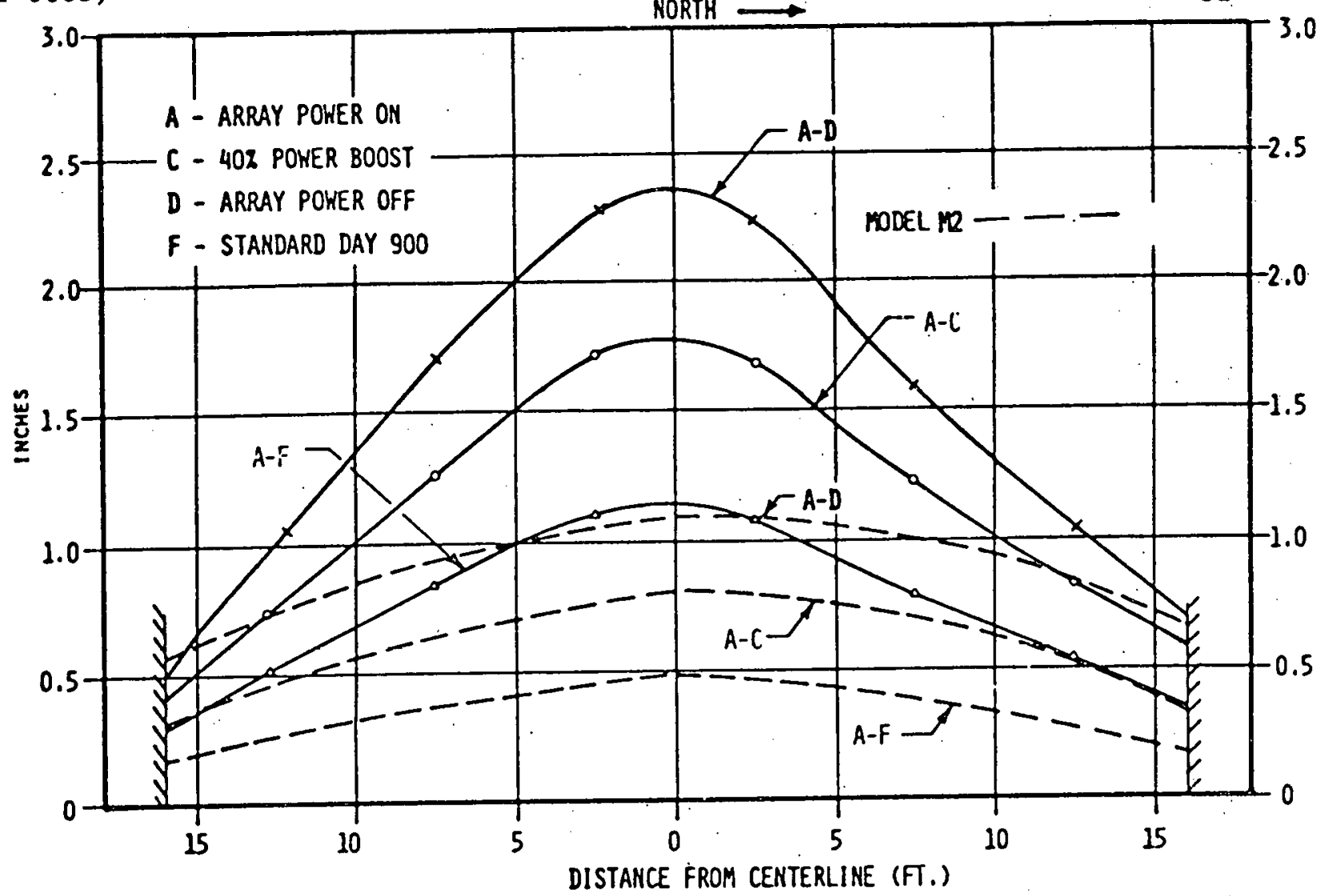

Figure 4.16.Floor Uplift Profiles at Selected Times; Model M2 - Room 1.

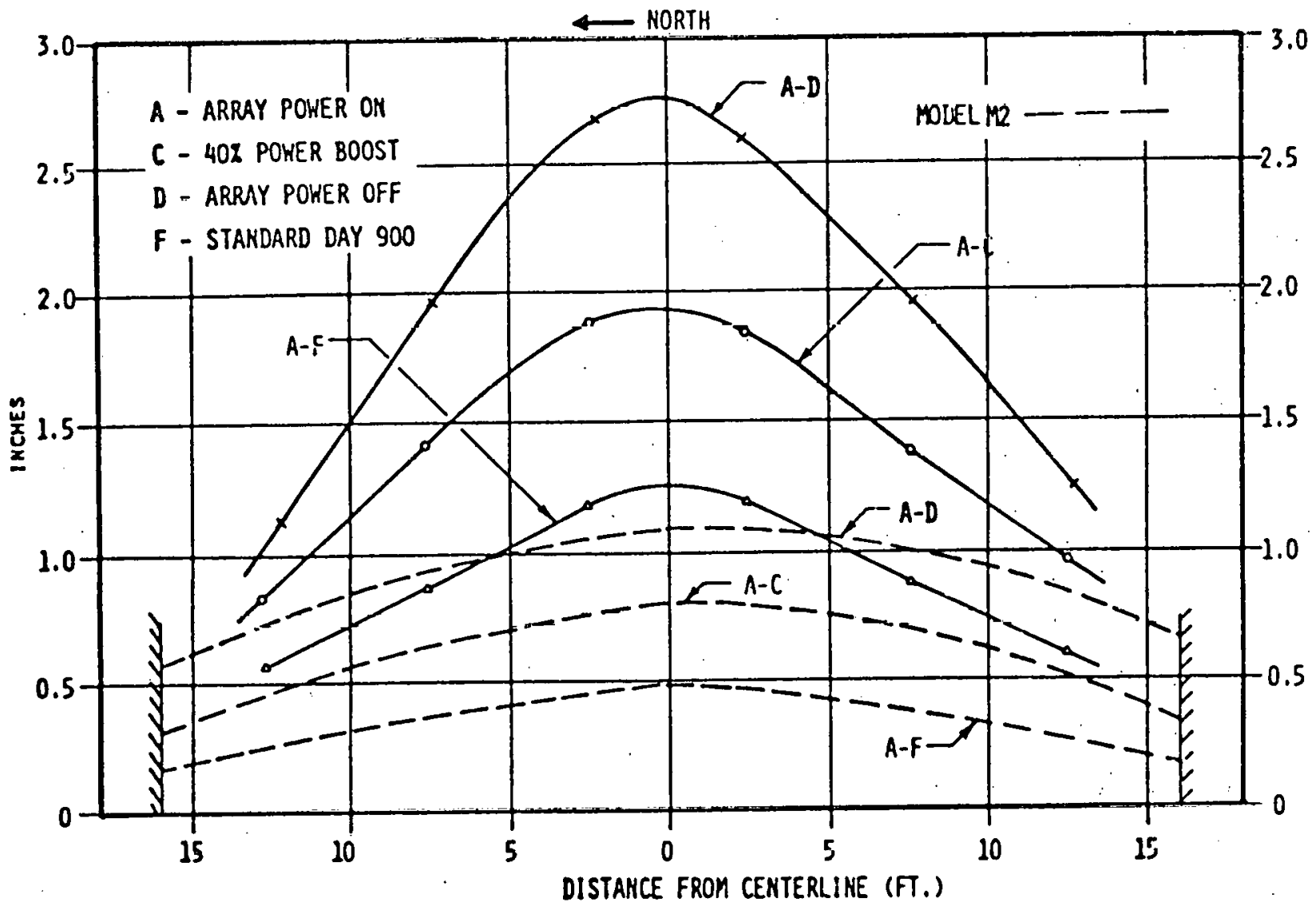

Figure 4.17. Floor Uplift Profiles at Selected Times; Model M2-Room 4. 


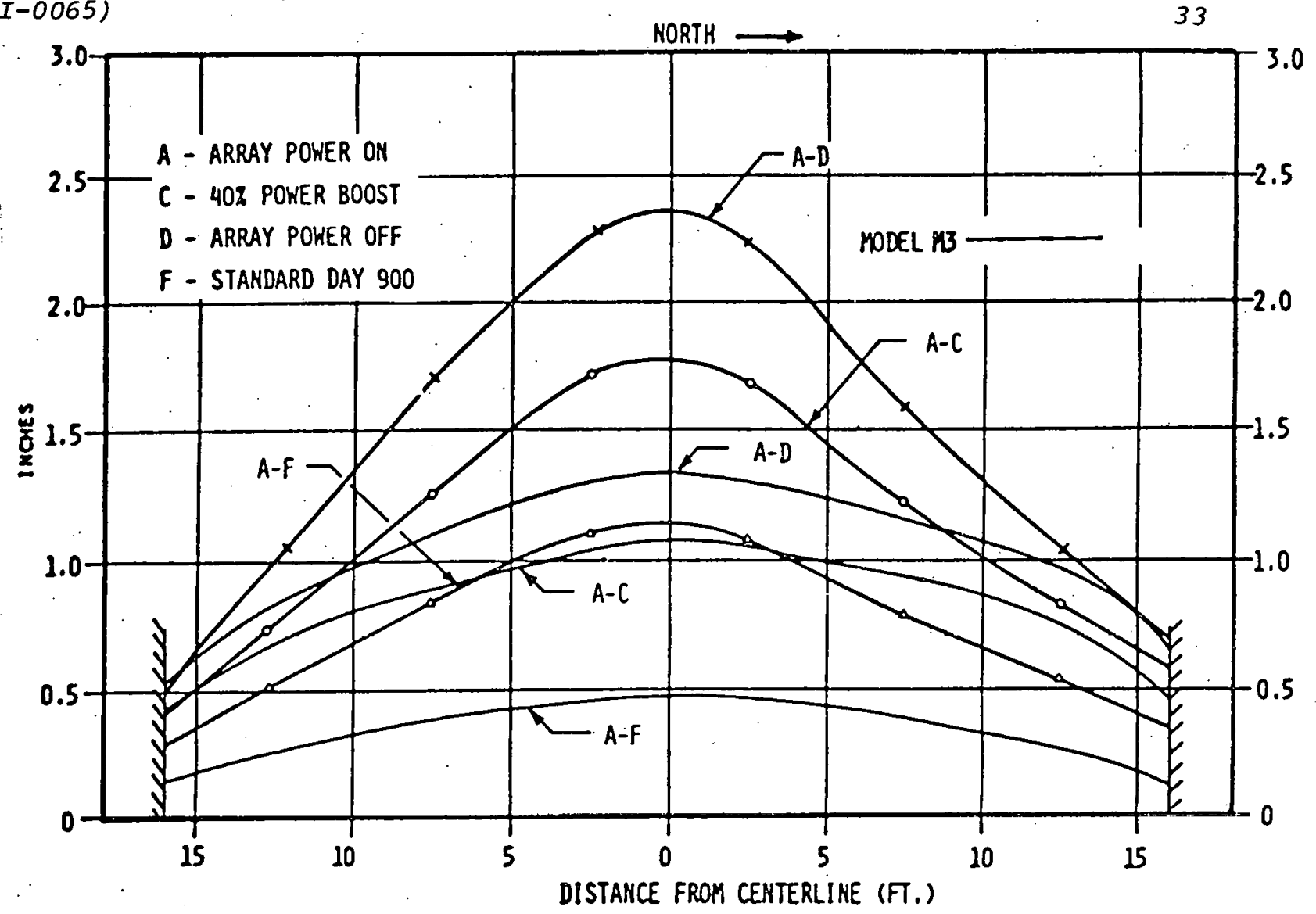

Figure 4.18.Floor Uplift Profiles at Selected Times; Model M3- Room 1.

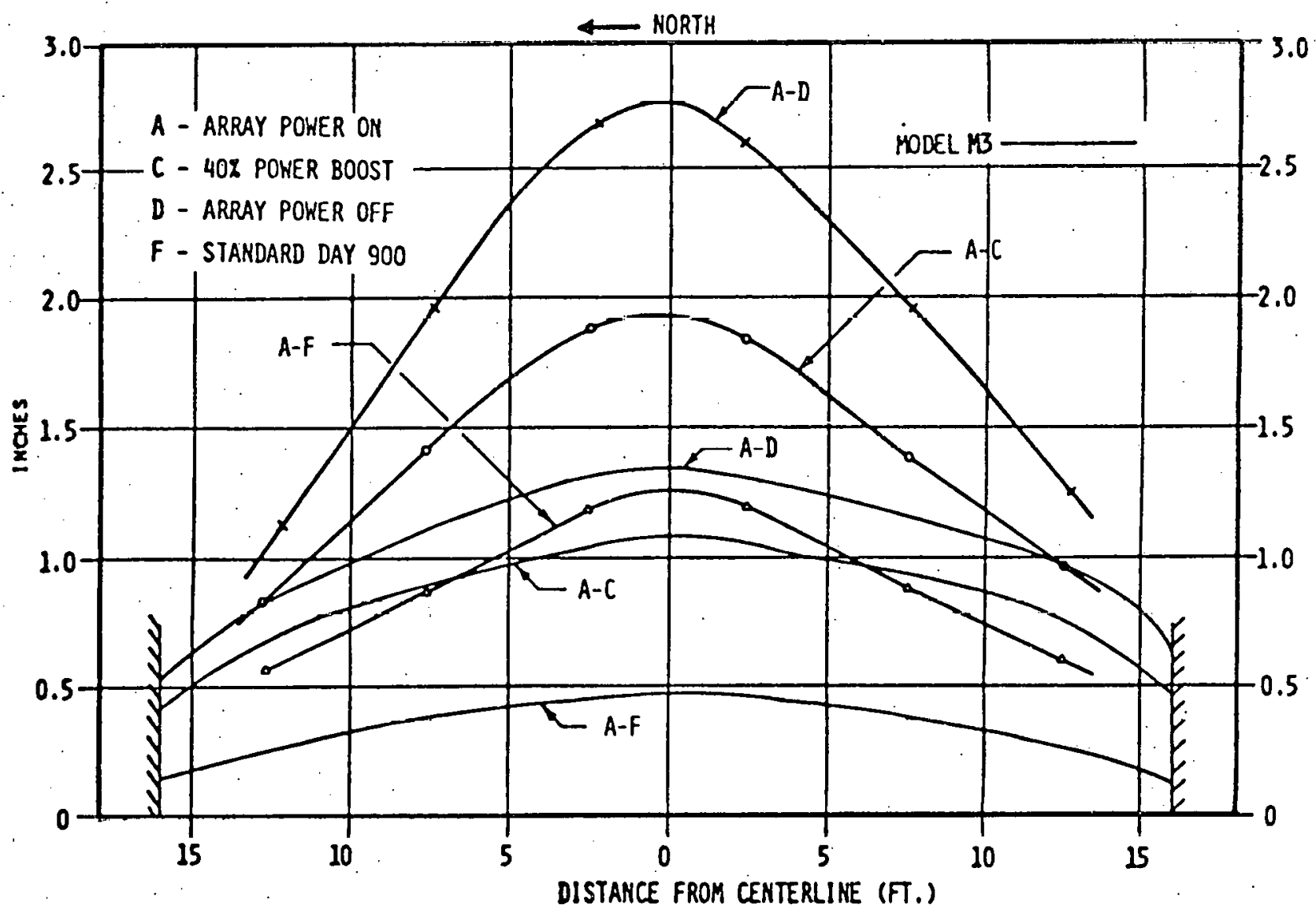

Figure 4.19. Floor Uplift Profiles at Selected Times; Model M3-Room 4. 


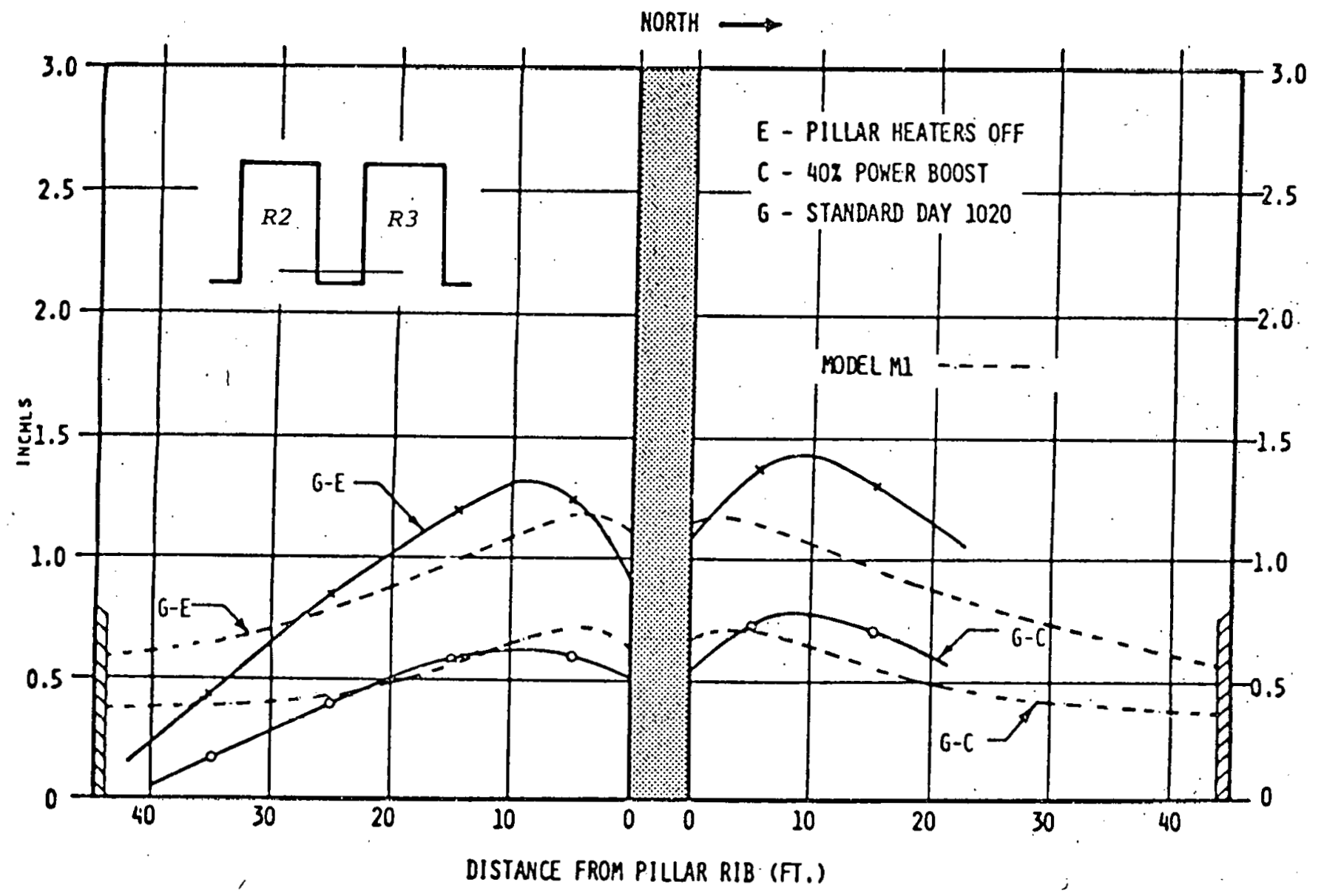

Figure 4.22. Floor Uplift Profiles in Rooms 2 and 3 Across the Heated Pillar (Front Section); Model Ml. 


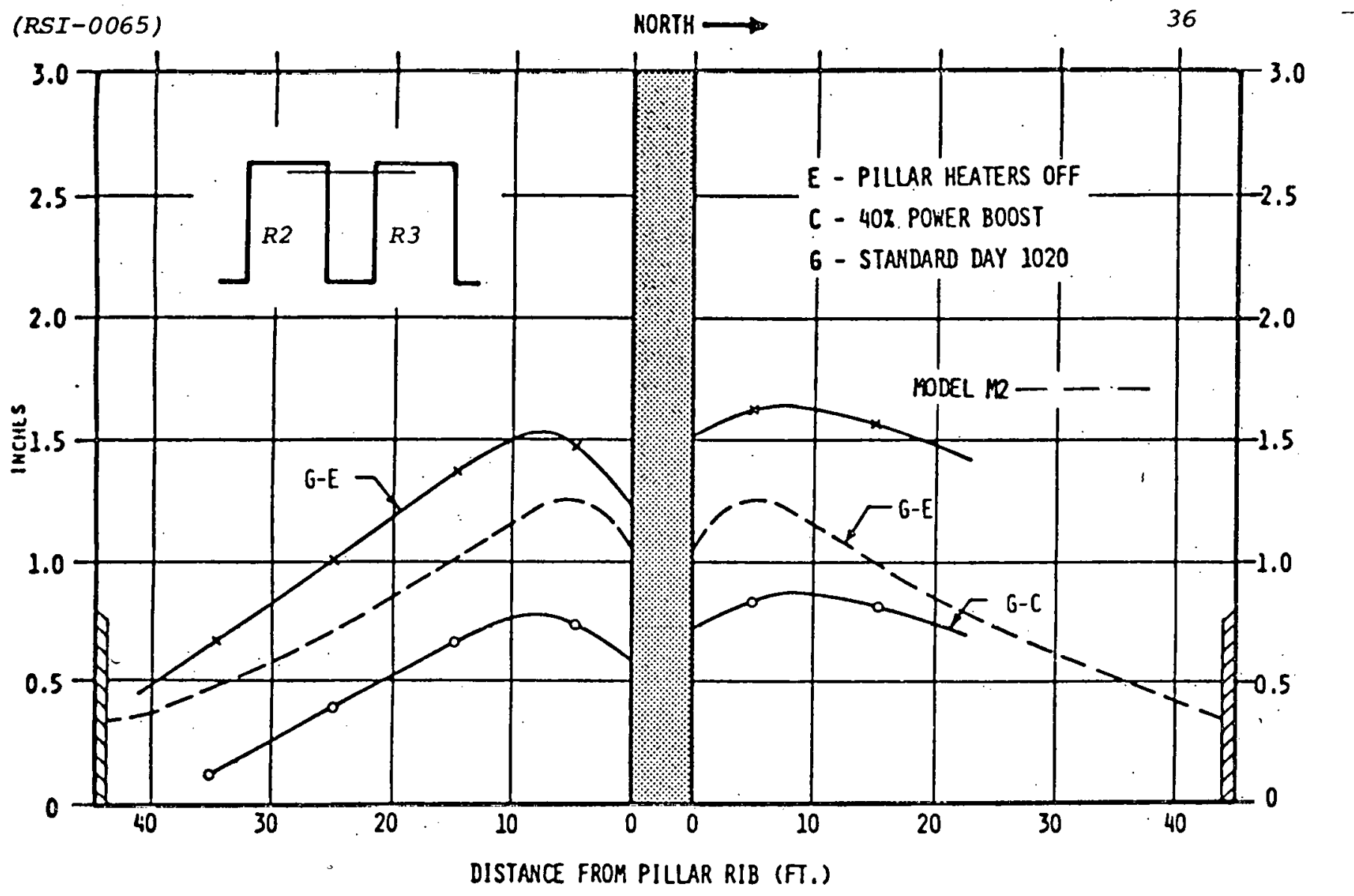

Figure 4.23. Floor Uplift Profiles in Room 2 and 3 Across the Heated Pillar (Back Section); Model M2.

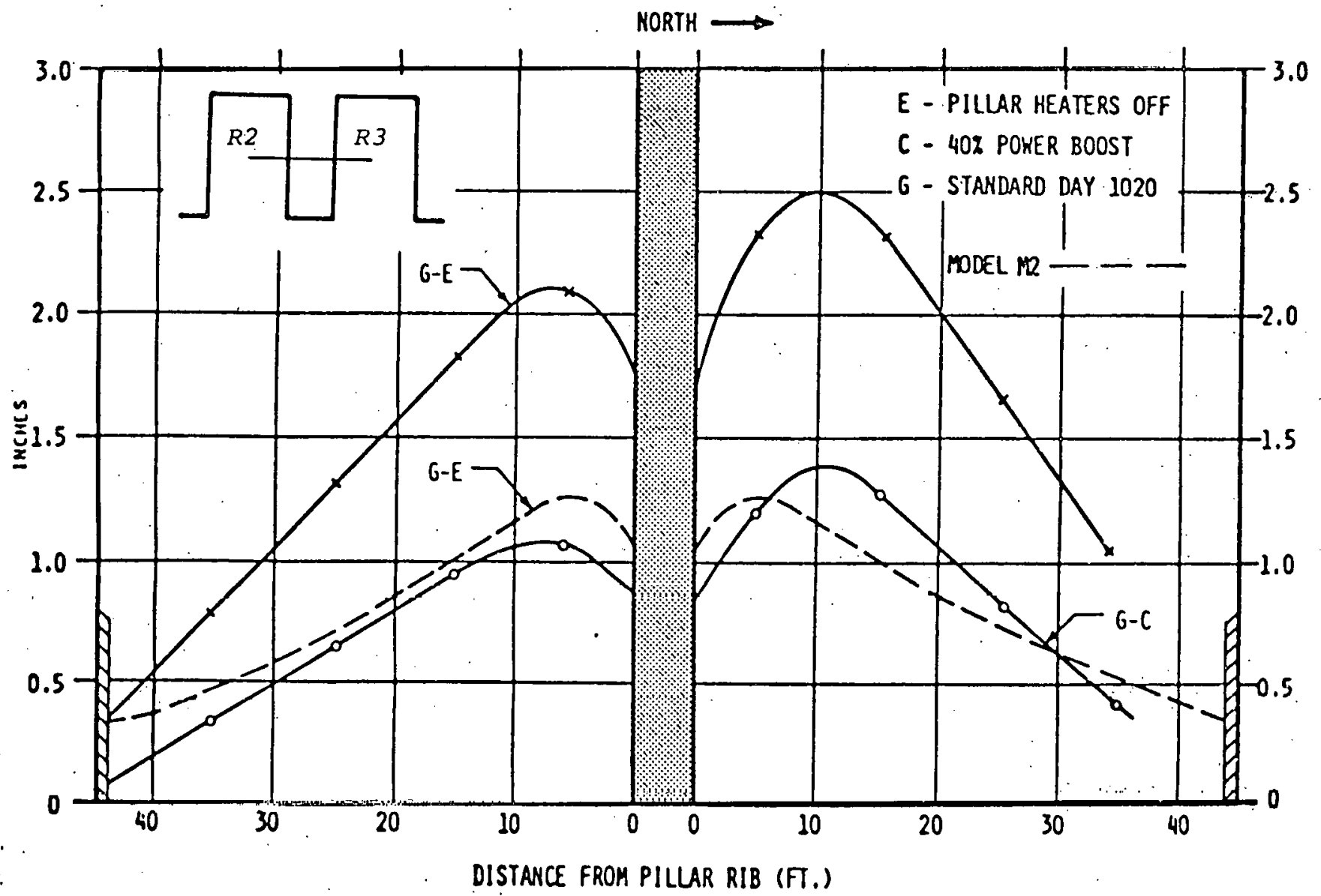




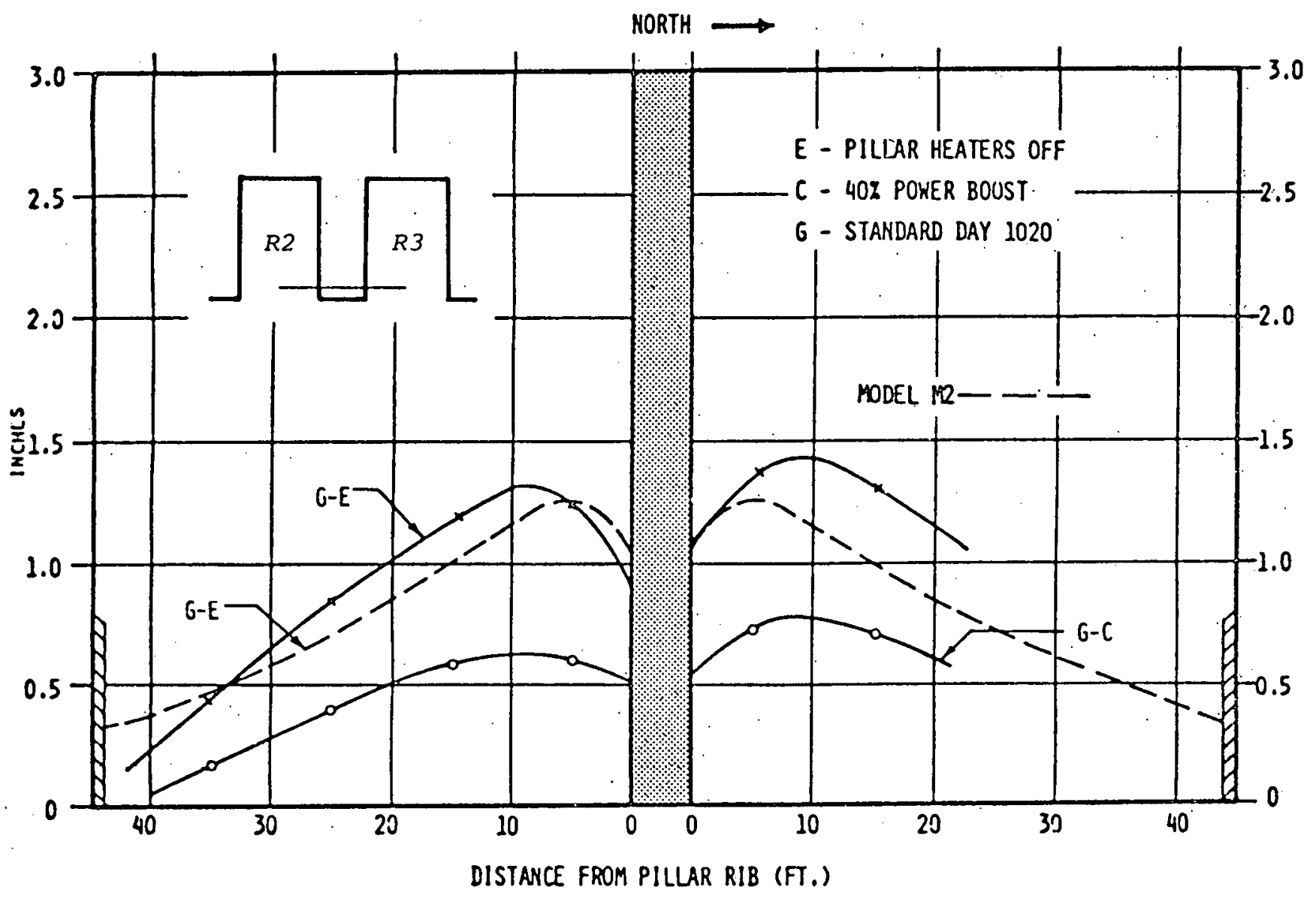

Figure 4.25.Floor Uplift Profiles in Rooms 2 and 3 Across the Heated Pillar (Front Section); Model M2. 


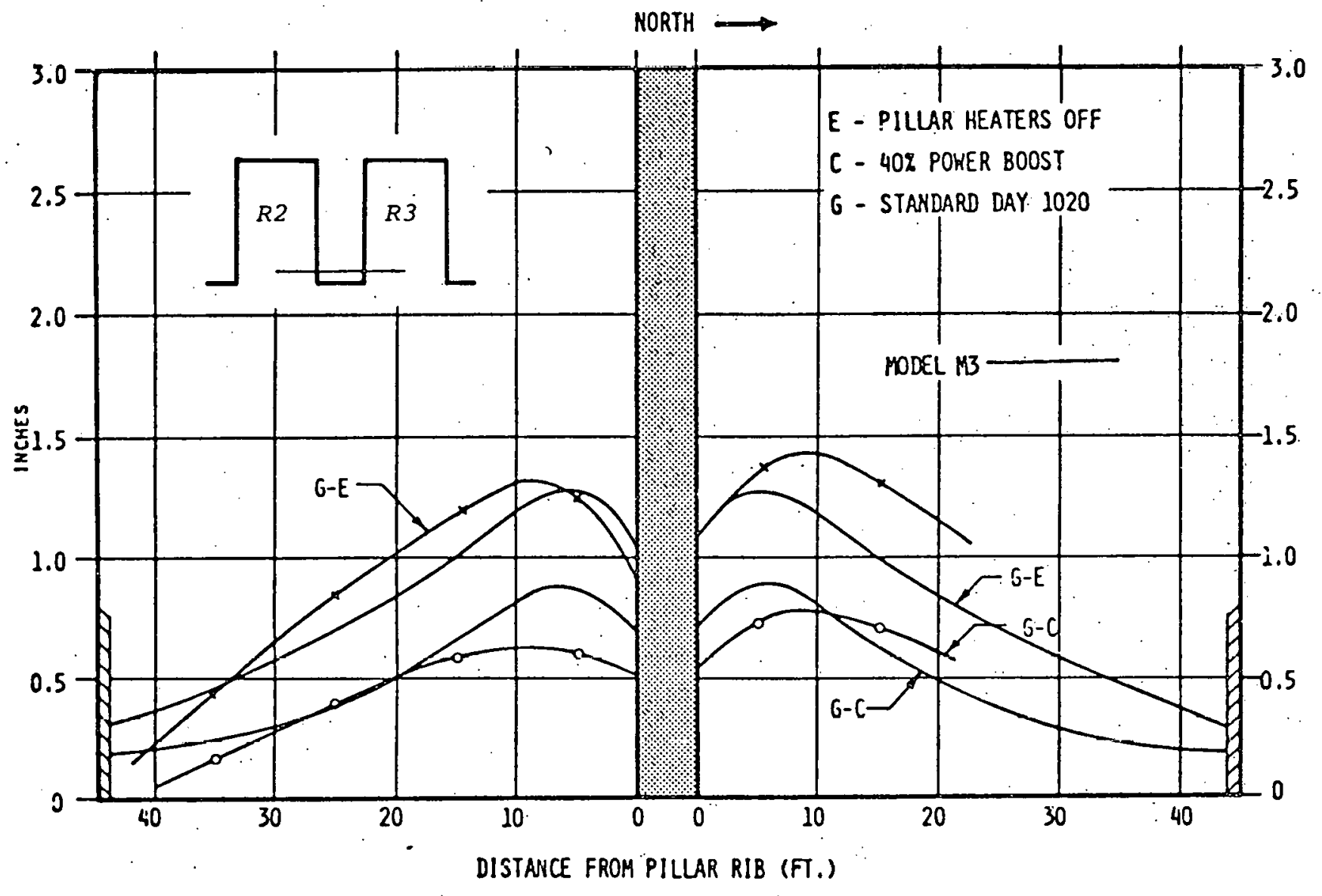

Figure 4.28: Floor Uplift Profiles in Room 2 and 3 Across the Heated Pillar (Front Section); Model M3. 


\subsection{Horizontal Pillar Deformation}

As was mentioned previously, wire extensometers were utilized in all of the pillars (including the barrier pillars) in the PSV experimental area in order to measure horizontal pillar deformation. The extensometers in the barrier pillars were anchored at a location which was believed to be unaffected by the experimental area.

The resulting horizontal deformation measured at the midheight of the barrier pillars on either end of the PSV area is displayed in Figure 4.29. In addition to the field measured data, the results from Models $M 2$ and $M 3$ are also illustrated in this figure. As can be readily observed, the finite-element results do not appear to follow the magnitude or slope of the barrier pillar deformation. Two observations which may account. for a portion (if not all) of the discrepancy can be noted. Firstly, the extensometer anchor location may, in fact, have moved horizontally away from the experimental area during the heating events. It will be shown later that corrections for extensometer anchor location movement result in much better agreement between simulation and field results. secondly, the finite element model does not actually represent the barrier pillars as they existed in the PSV area. Specifically, the model assumes that the barrier pillar is restrained from lateral movement on the side farthest from the experimental area. However, in the mine, both barrier pillars separated the experimental area from haulageways ${ }^{(9)}$.

The measured horizontal movement of the rib of pillar 1-2 into room 1 is presented in Figures 4.30 and 4.31. The simulation results for Models $M 2$ and $M 3$ are also presented in Figure 4.30 and Model $M 3$ is repeated in Figure 4.31. However, in Figure 4.31, absolute horizontal rib displacements from Model $M 3$ are compared to the experimental data; whereas in Figure 4.30, the simulation results from Models $M 2$ and $M 3$ are obtained by referencing the model rib displacement to the model displacement at the center of the pillar. The assumption inherent to this analysis is that the center of the pillar did move during the PSV experiment and that the models adequately represent that movement. In 
this particular situation, the effect of the correction for extensometer location is not particularly vivid; however, a more illustrative example will be shown later. The simulation models $M 2$ and $M 3$ and the measured results agree rather favorably in Figure 30. The comparison between simulation results and measured results is perhaps. somewhat better for the movement of pillar 3-4 into room 4 as illustrated in Figures 4.32 and 4.33. In both situations, the simulation models appear to agree more closely with the "stiffer" cross-section of the experimental area. The effect of the correction for extensometer anchor movement is quite pronounced in Figures 4.34 and 4.35. These figures compare the horizontal movement of pillar 1-2 into room 2. This simulation data is also presented in Figures 4.36 and 4.37 wherein the PSV experiment results for the horizontal movement of pillar 3-4 into room 3 is presented. Once again, the model and measured results agree rather favorably with the exception that the model results do not indicate as pronounced a reaction to the initiation of the pillar heaters as is apparent in the measured results.

Since the center of pillar 2-3 was assumed to be a line of symetry in constructing the finite element model, no correction for extensometer anchor movement can be made to the model results. Figures 4.36 and 4.39 illustrate the horizontal movement of pillar 2-3 into room 2 for Models $M 2$ and $M 3$ and the PSV experiment results for movement of pillar 2-3 into room 2 and room 3, respectively. The magnitude of the simulation model results are relatively comparable to that which was measured. However, once again the measured results do not reflect the movement occurring between excavation and initiation of measurements. It is interesting to note that as was the case earlier, the rate of deformation exhibited in the models agrees well with the experimental results prior to activation of the pillar heaters. 
PSY STANDARD DAYS

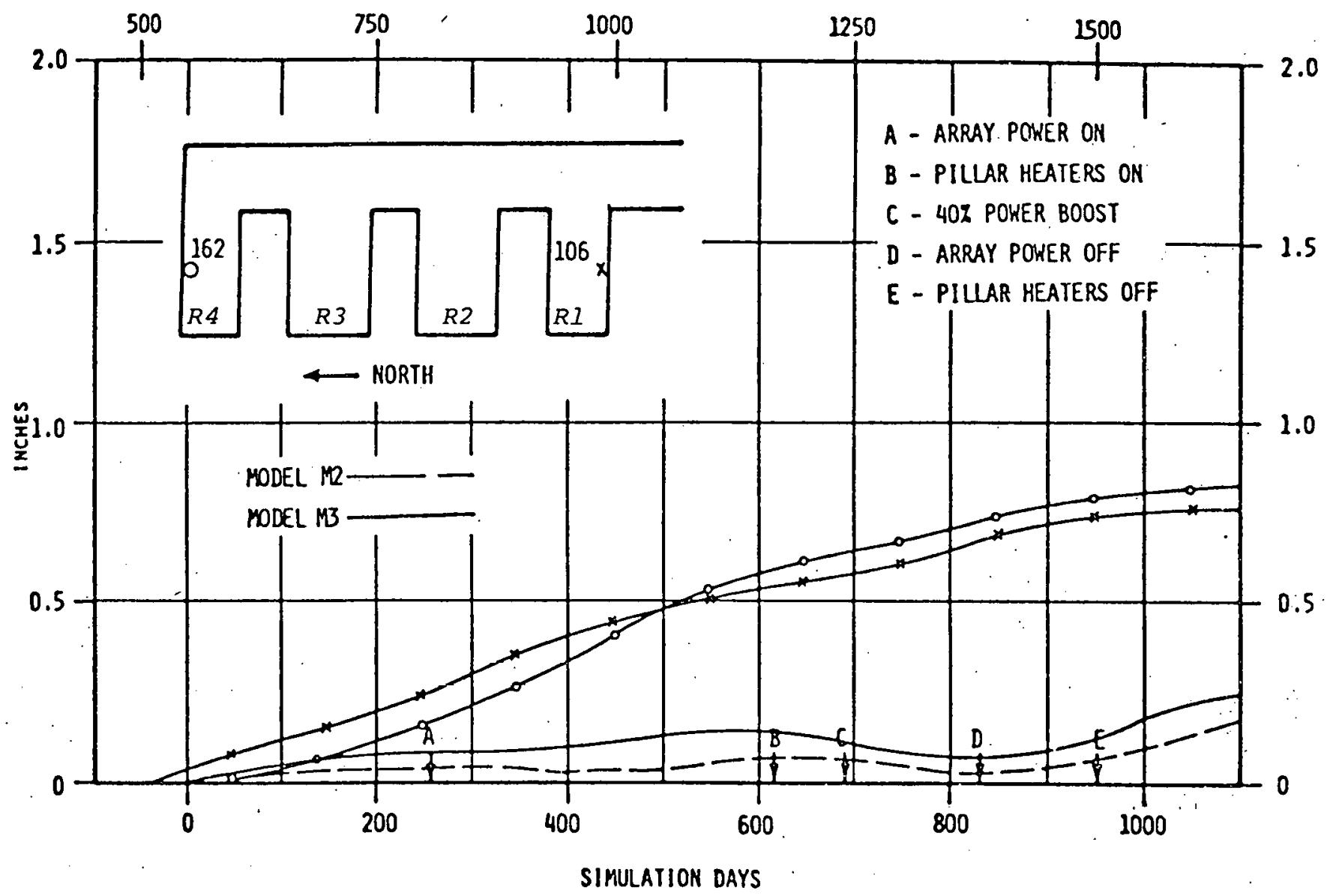

Figure 4.29. Horizontal Movement of Barrier Pillar Ribs. 
(RSI-0065)

PSY STANDARD DAYS

43

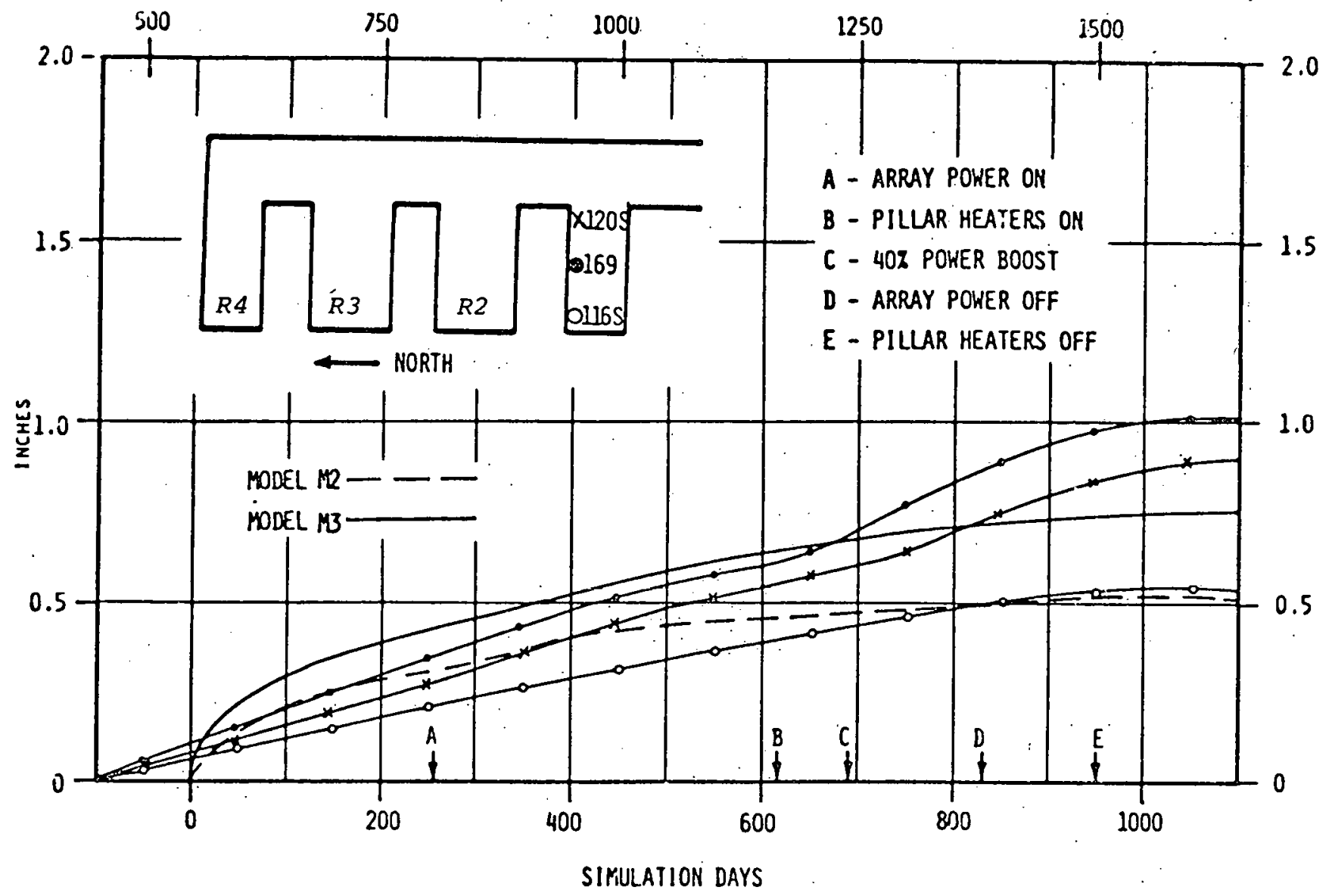

Figure 4.30. Horizontal Movement of Pillar 1-2 into Room 1 with Extensometer Anchor Correction.

PSY STANDARD. DAYS

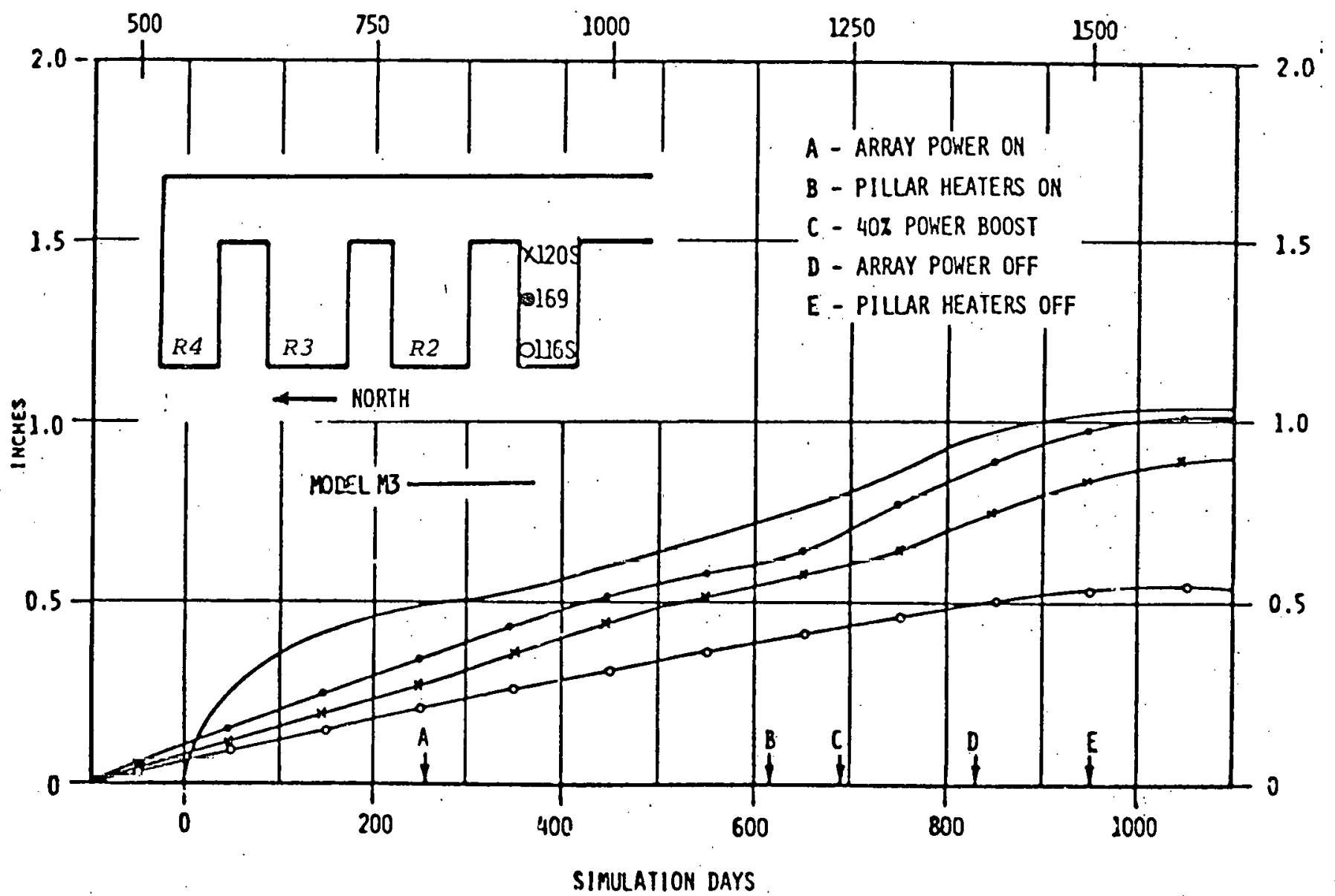

Figure 4.31. Horizontal Movement of Pillar $1-2$ into Room 1 without Extensometer Anchor Correction. 
$(R S I-0065)$

PSY STANDARD DAYS

44

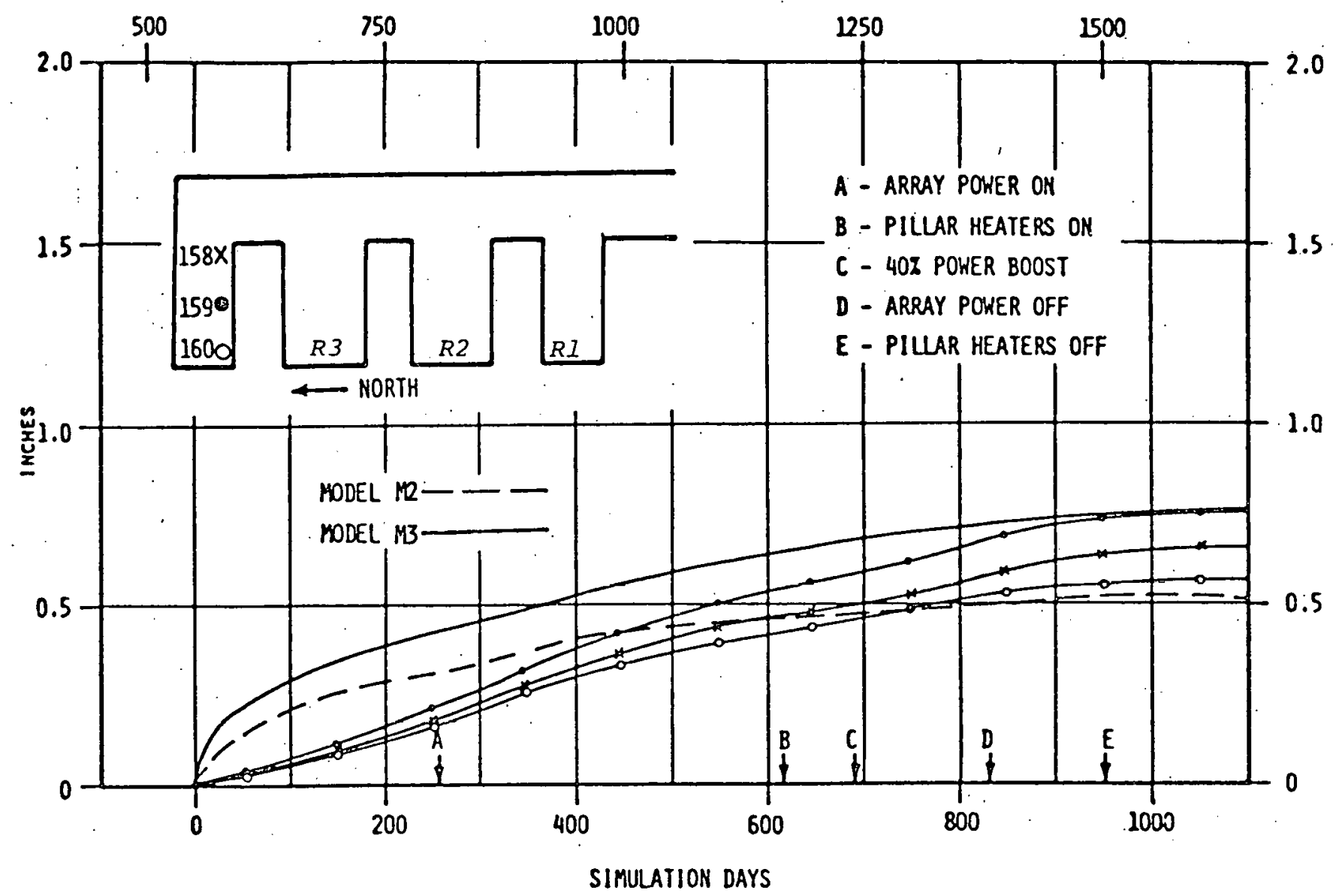

Figure 4.32. Horizontal Movement of Pillar 3-4 into Room 4 with Extensometer Anchor Correction.

PSV STANDARD DAYS

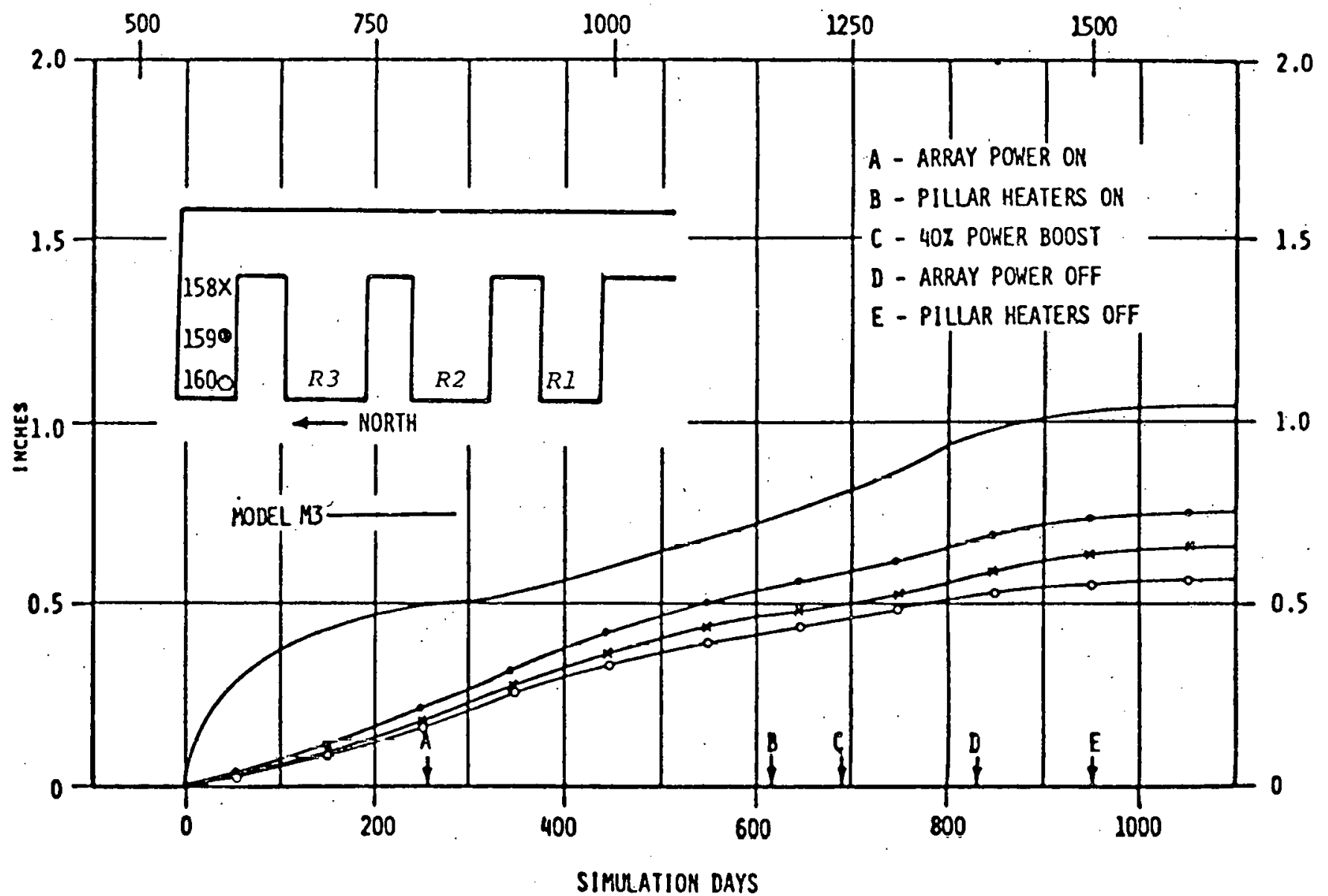

Figure 4.33. Horizontal Movement of Pillar 3-4 into Room 4 without Extensometer Anchor Correction. 
(RSI-0065)

PSV STANDARD DAYS

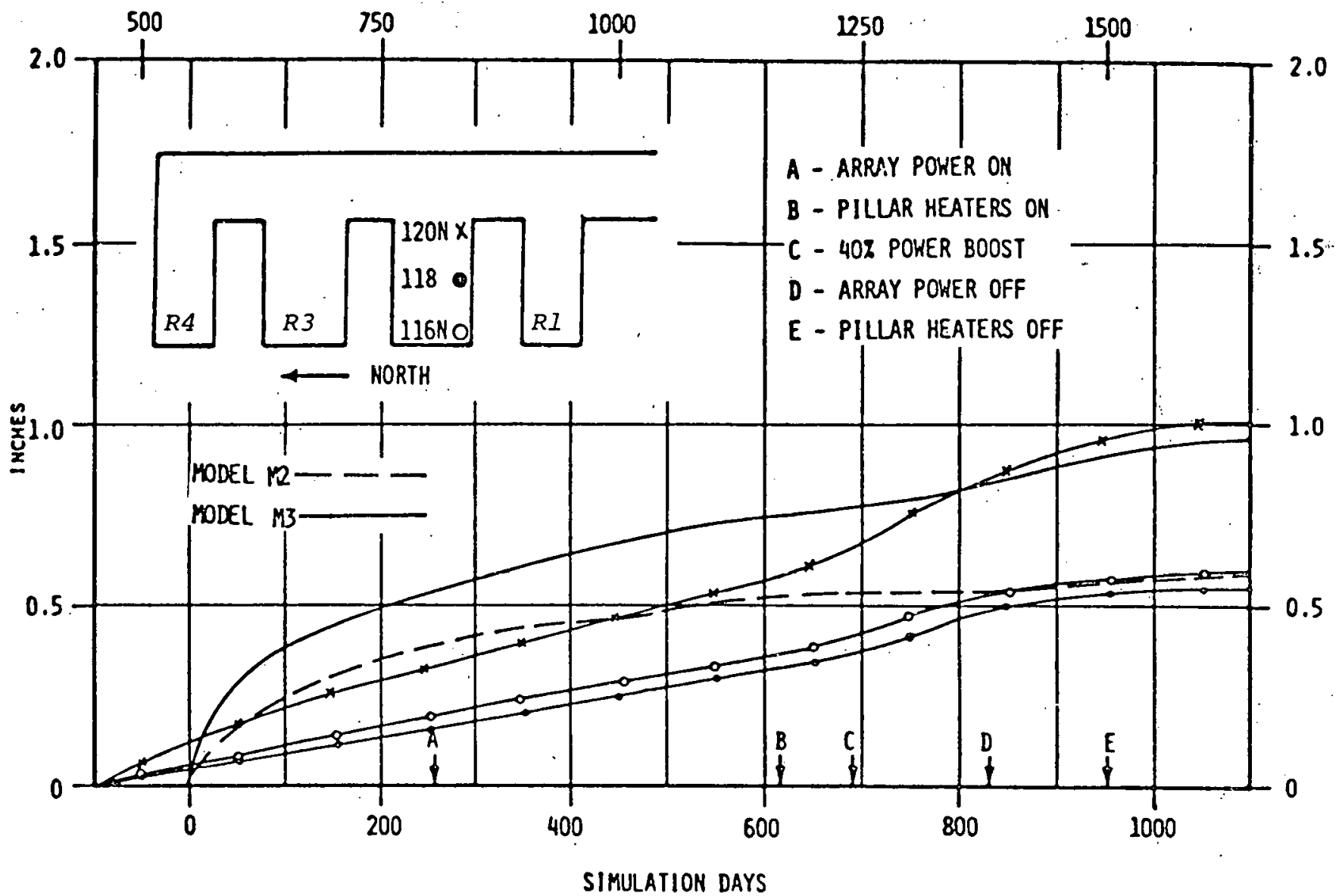

Figure 4.34. Horizontal Movement of Pillar 1-2 into Room 2 with Extensometer Anchor Correction.

PSV STANDARD DAYS

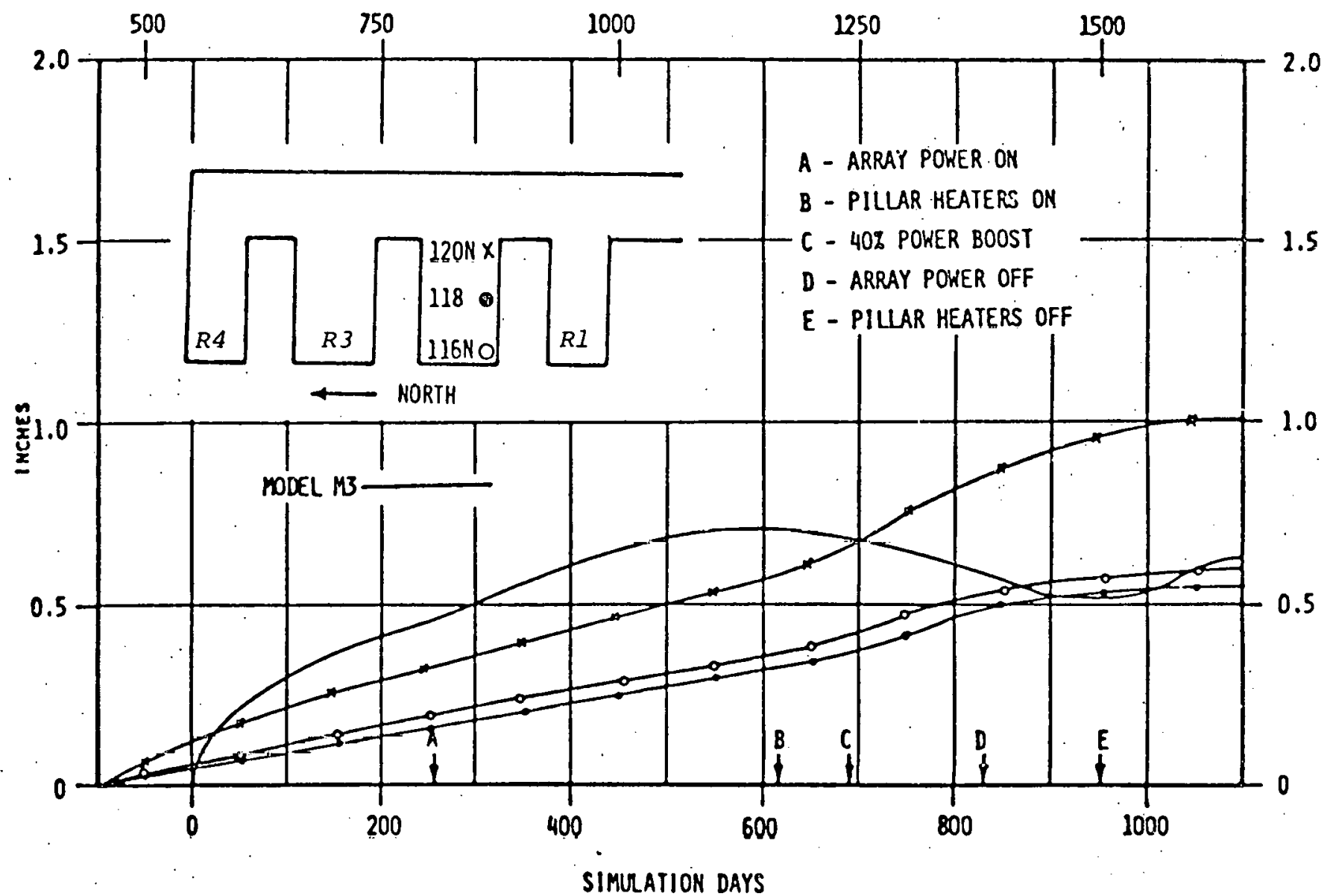

Figure 4.35. Horizontal Movement of Pillar 1-2 into Room 2 Without Extensometer Anchor Correction. 
(RSI-0065)

PSV STANDARD DAYS

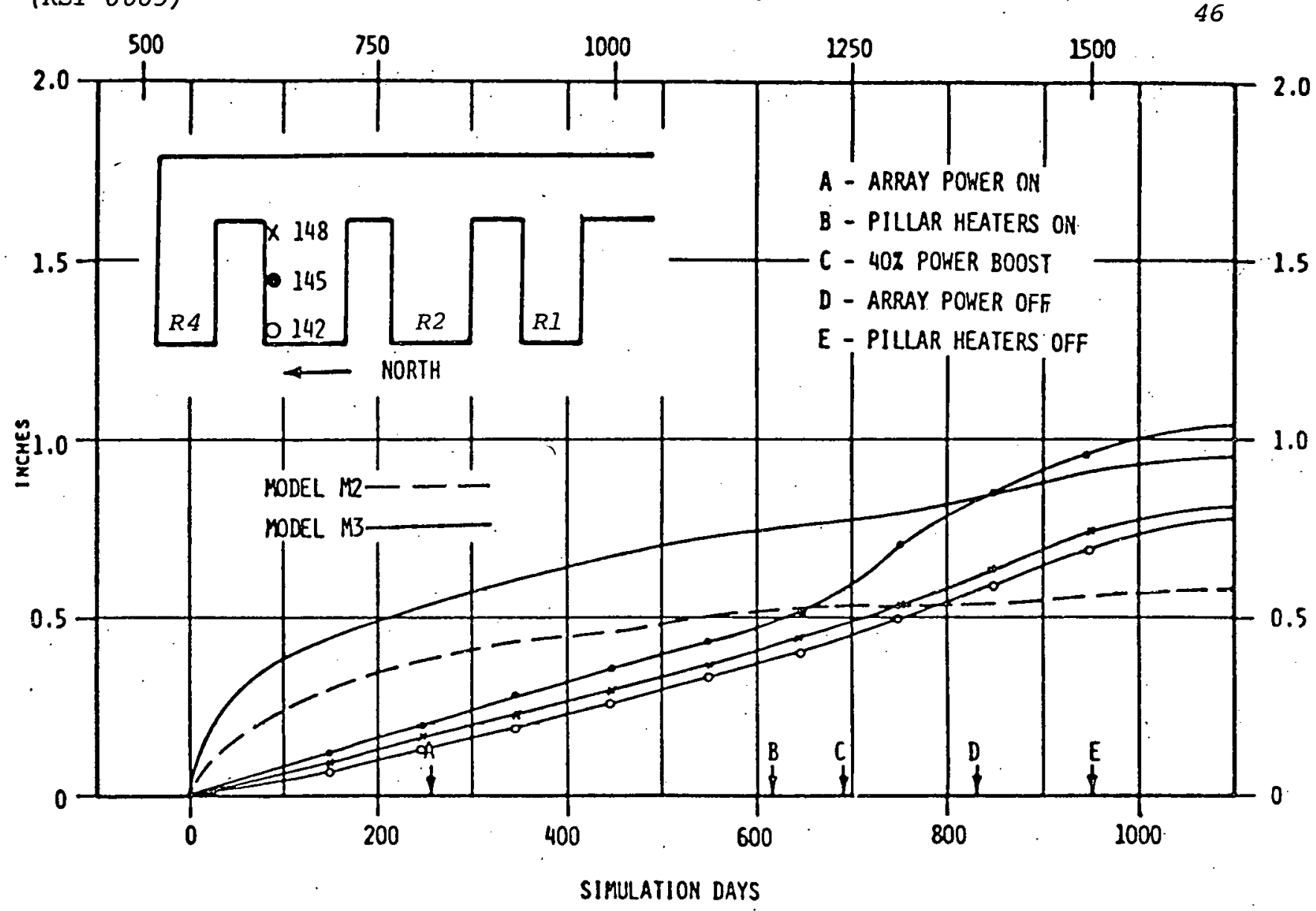

Figure 4.36. Horizontal Movement of Pillar 3-4 into Room 3 with Extensometer Anchor Correction.

PSY STANDARD DAYS

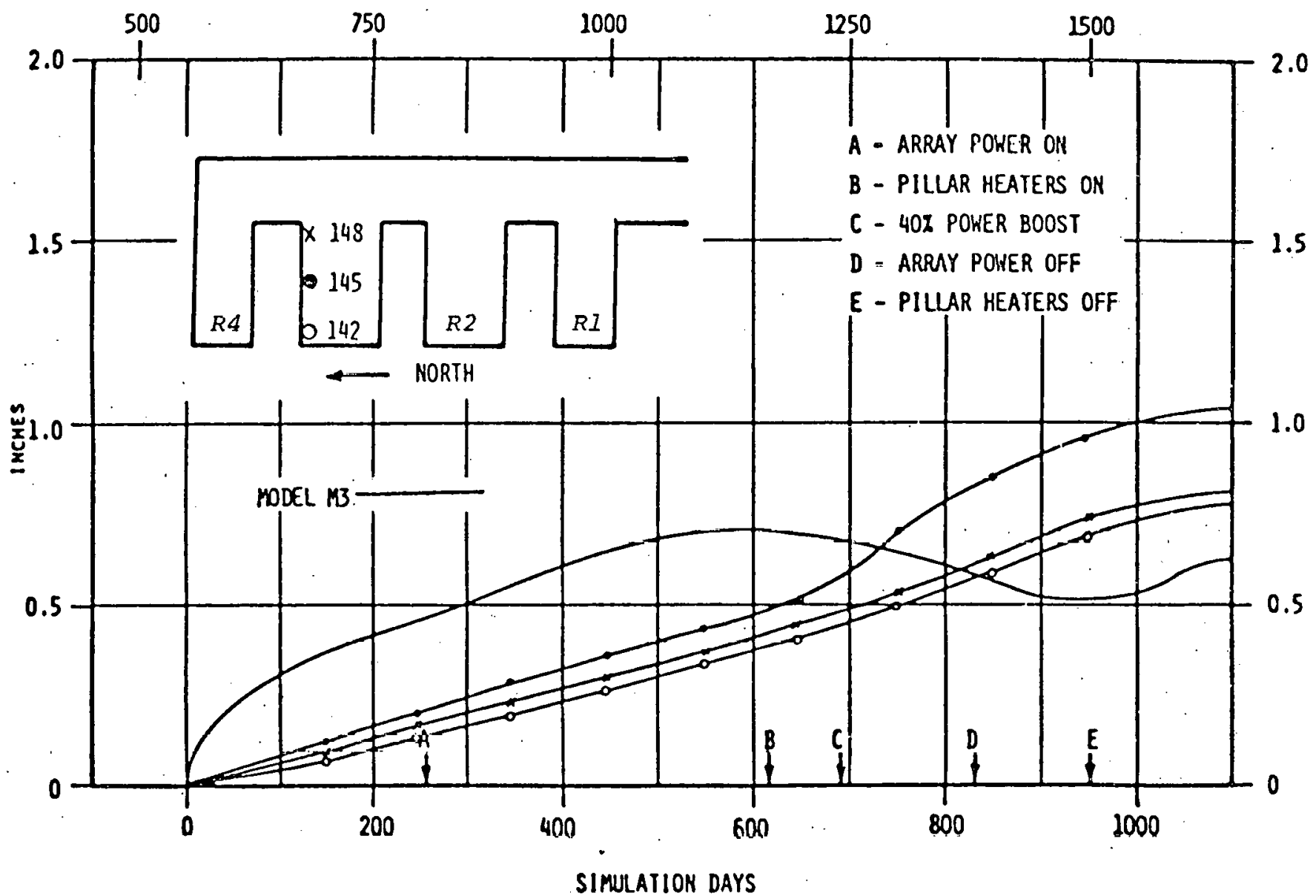

Figure 4.37. Horizontal Movement of Pillar 3-4 into Room 3 Without Extensometer Anchor Correction. 


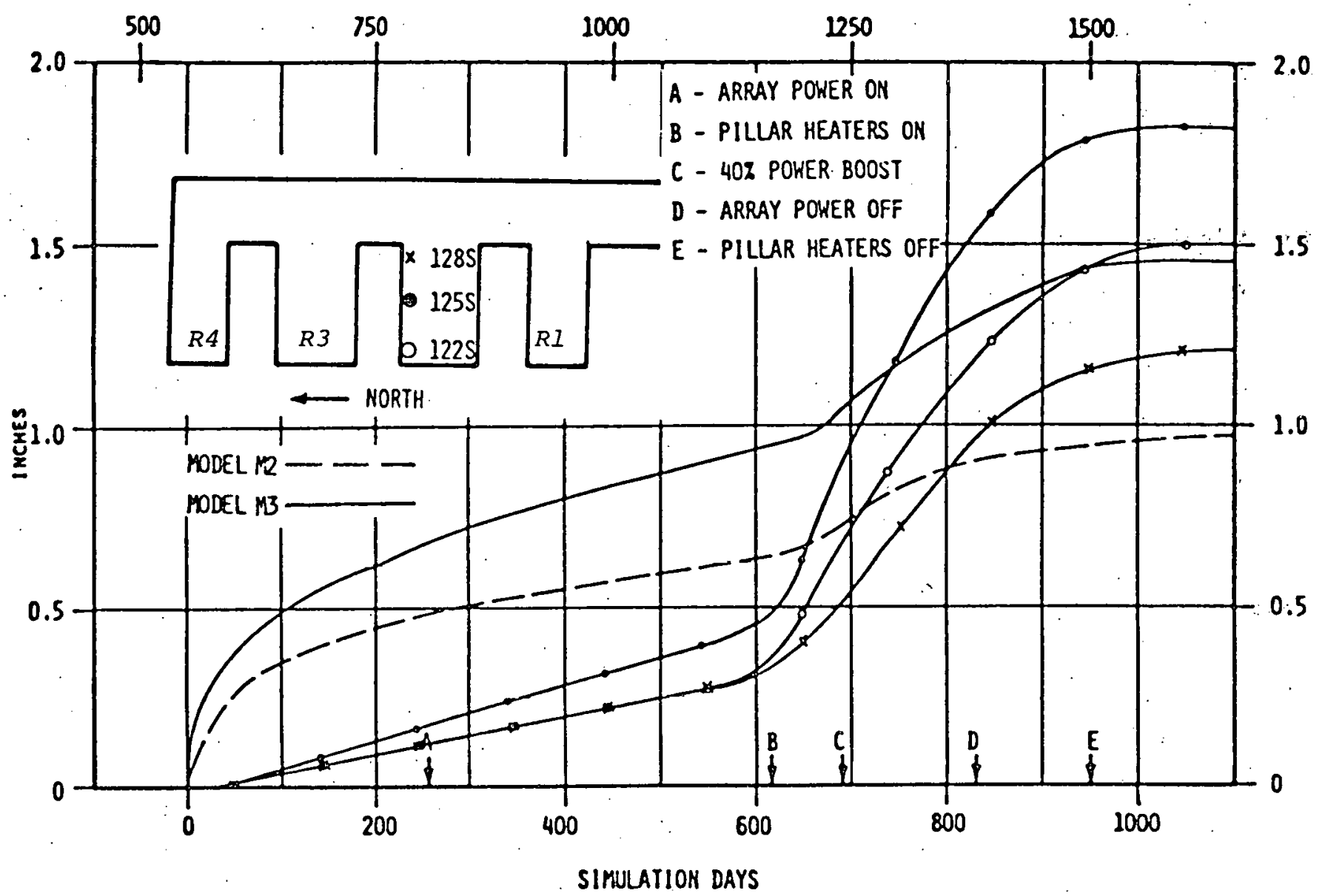

Figure 4.38. Horizontal Movement of Pillar 2-3 into Room 2.

PSV STANDARD DAYS

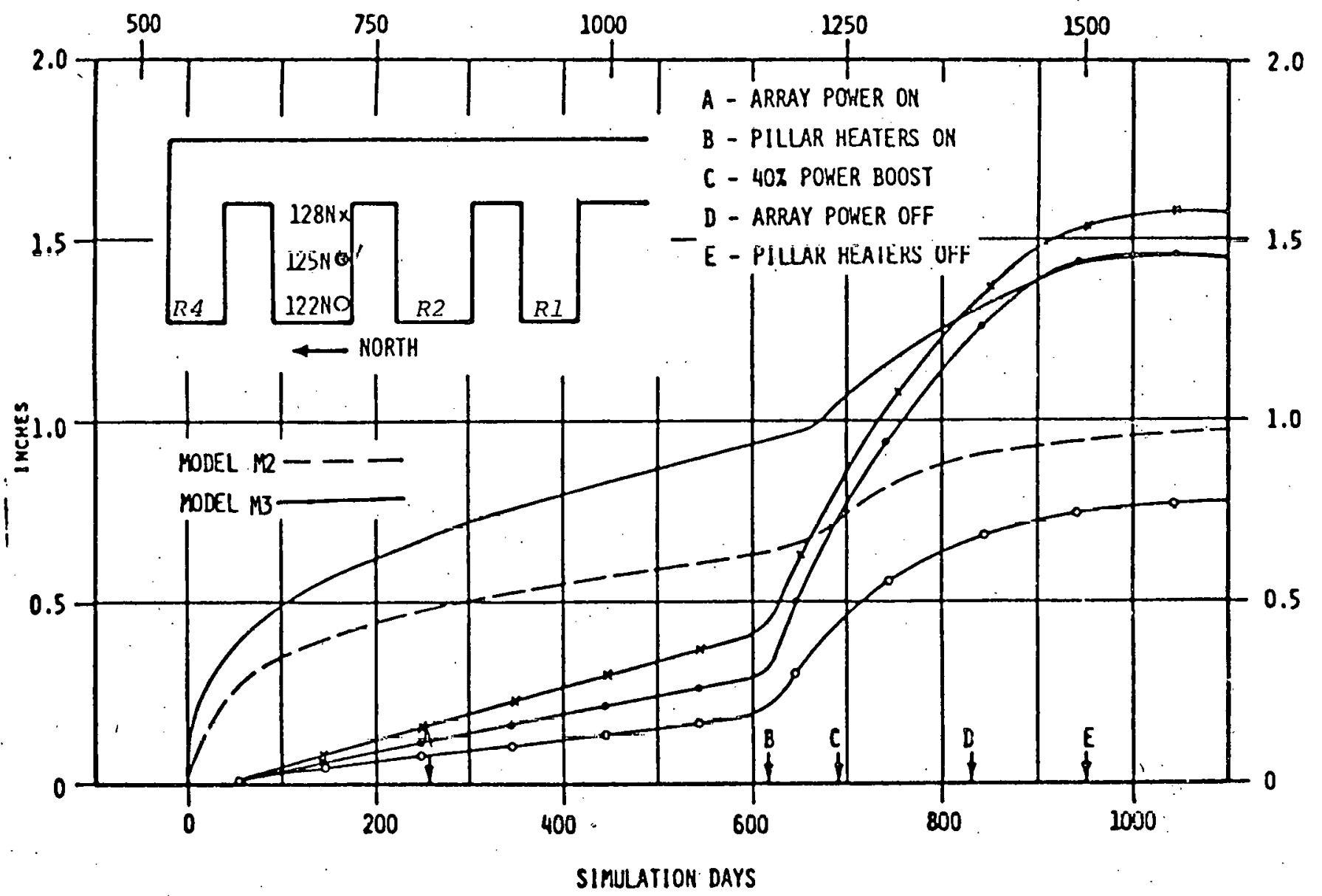

Figure 4.39. Horizontal Movement of Pillar 2-3 into Room 3. 
5. COMPARISON OF UNIAXIAL PILLAR SHORTENING WITH ROOM CONVERGENCE

In an effort to assess the degree of difficulty in predicting the results of the Project Salt Vault Experiment, a simple uniaxial model of the PSV pillars was analyzed. Specifically, a uniaxial model of the pillars was constructed under the following assumptions:

(1) the average vertical stress in a pillar could be calculated on the basis of the extraction ratio in the vicinity of the pillar (13);

(2) the horizontal or confining stress in the pillar is negligible;

(3) the mean temperature in the uniaxial pillar could be taken to be the average of the lower half of the pillar from the finite element Model M3;

(4) the vertical deformation or shortening of the uniaxial pillar could be calculated from Equation [1] of section 3.3.

Under these assumptions, the excavation time for the uniaxial model can be coincident with the time of excavation near the respective pillar being modeled, since each uniaxial model is independent of any other pillar. Pillars 1-2, 2-3, and 3-4 were examined with the uniaxial model. The results of this analysis are presented in Figures 5.1 through 5.4, together with the PSV and Models M2 and M3 convergence results. As can be seen in the figures, the pillar shortening predicted by the uniaxial model and the convergence near the pillars measured in PSV agree very well. The good agreement between the uniaxial model pillar shortening and the measured convergence exists because:

(1) the uniaxial model inherently does not possess the stiffness due to the roof and floor which is present in the finite element models;

(2) the convergence in PSV does appear to always be transient and well represented by a constitutive law of the form of Equation [1] from Section 3.3.

The results presented in this section should, however, be viewed with some scrutiny. The PSV and finite element results presented in Figures 5.1 through 5.4 are actually for convergence, and as such represent both pillar shortening and some roof sag and floor heave, for an excavation in salt involving elevated temperature. The uniaxial results only represent pillar shortening. Also, the assumption of negligible confining stress in the uniaxial model is not necessarily correct. This uniaxial analysis was presented, however, in an effort to display the fact that the PSV experiment is a field situation that is not difficult to model with a numerical method. 
(RSI-0065)

PSV STANDARD DAYS

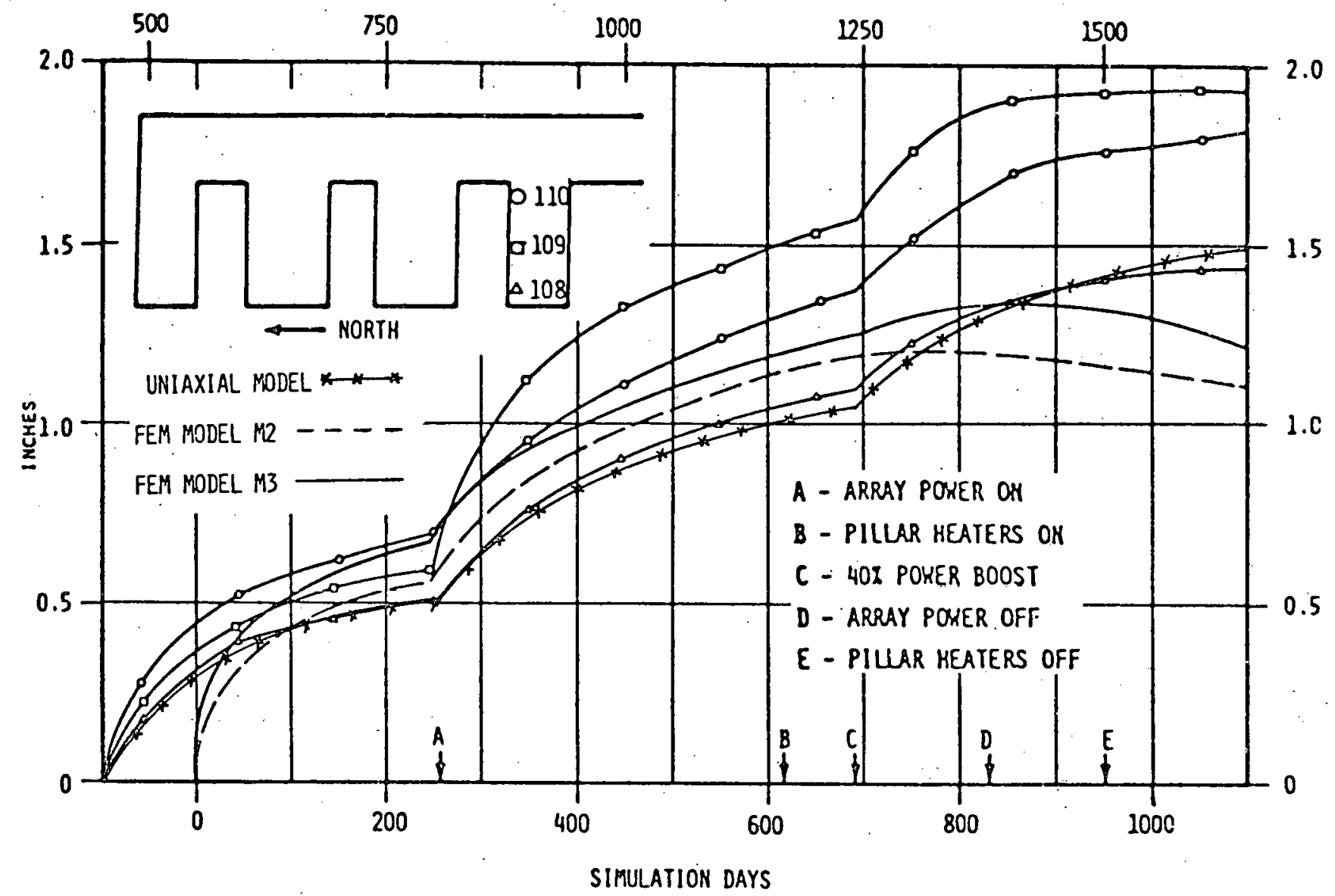

Figure 5.1. Comparison of Pillar 1-2 shortening to Convergence in Room I Near Pillar I-2.

PSY STANOARD DAYS

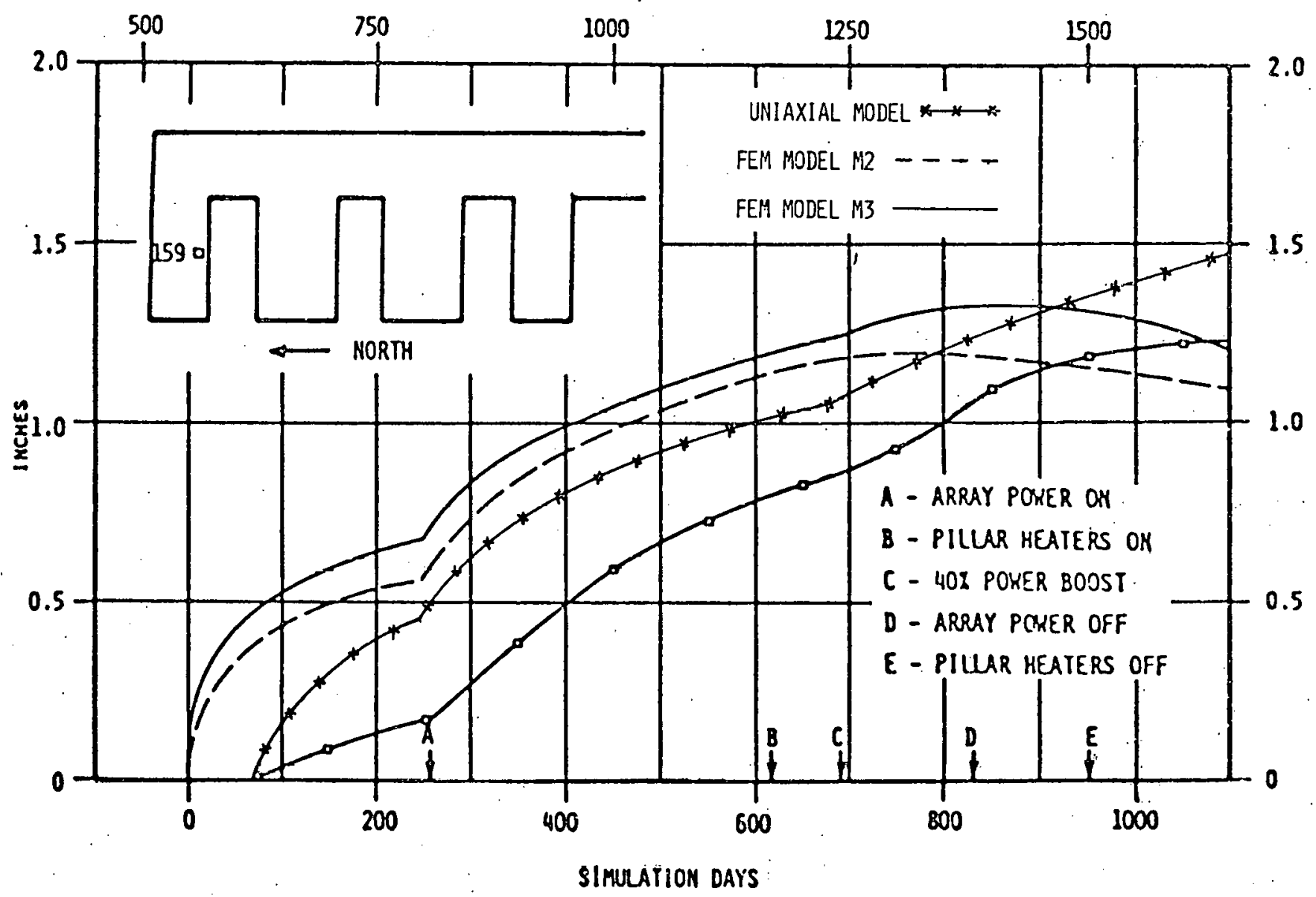

Figure 5.2. Comparison of Pillar 3-4 Shortening to Convergence in Room 4 Near Pillar 3-4. 
(RSI-0065)

PSY STANDARD DAYS

50

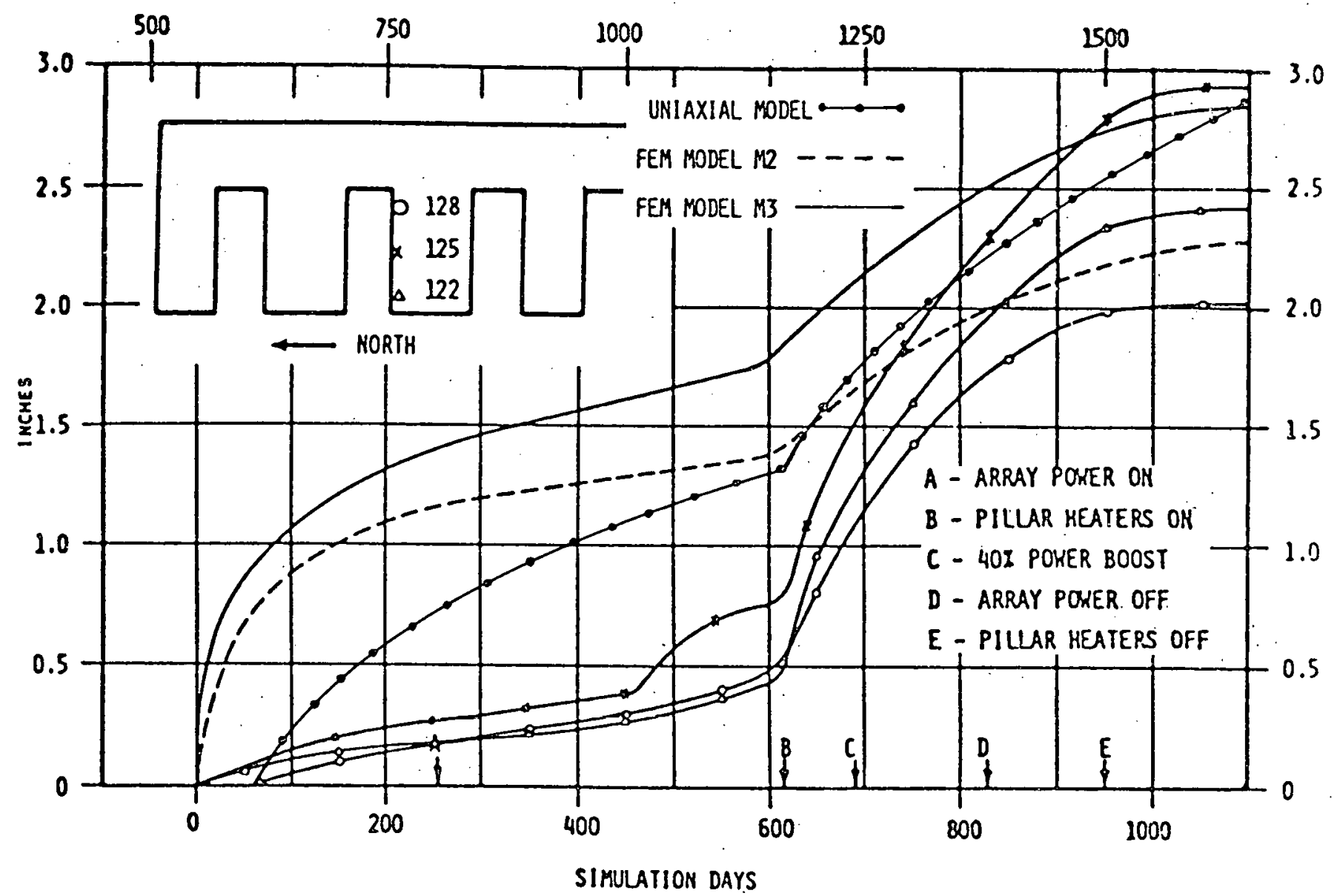

Figure 5.3. Comparison of Pillar 2-3 shortening to Convergence in Room 2 Near Pillar 2-3.

PSV STANDARD DAYS

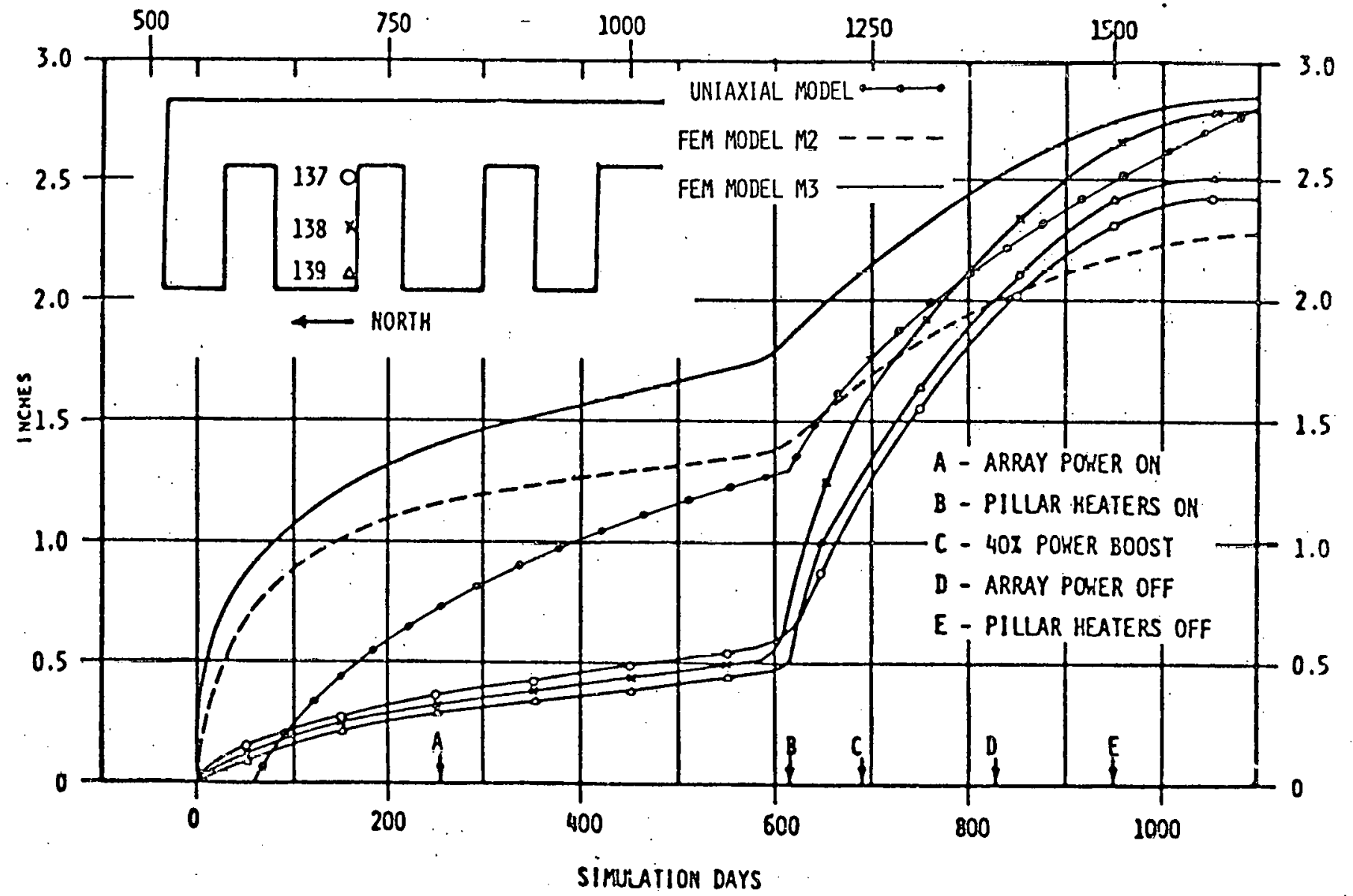

Figure 5.4. Comparison of Pillar 2-3 shortening to convergence in Room 3 Near Pillar 2-3. 


\section{SUMMARY AND CONCLUSIONS}

Two thermoviscoelastic finite element models and one thermoelastic model were used to simulate the Project salt vault experiment. All models were two dimensional, assumed plane strain normal to the plane of the model, and also assumed symetry of Project salt Vault about. the center of pillar 2-3. The entire mining sequence was not simulated; rather the rooms were instantaneously excavated. The excavations were then allowed to creep for 0.66 years at which time the Project Salt vault heating cycle was initiated and the thermo/viscoelastic simulation continued.

Within the limitations of the assumptions in the construction of the models, the comparison between the simulation models and the measured results is generally good. Specific instances where the model results were not considered good included the horizontal displacement of the barrier pillars and the inadequacy of the models to represent the total permanent deformation exhibited in the experiment results.

In practically all instances where discrepancies exist between model and measured results, several logical hypothesis can be brought forth. Due to the complexity of the actual situations in the Project salt vault experiment (material inhomogeneities, geometrical situations and asymetry), no single hypothesis can be, however, absolutely proved nor disproved. 


\section{LIST OF REFERENCES}

1. Callahan, G. D.: "Thermo/Viscoelastic Analysis of the Waste-Container Sleeve: I. Time-Dependent Salt Loading on the Sleeve and Closure of the Drillhole", Technical Memorandum Report RSI-0020, Prepared for Holifield National Laboratory under Subcontract No. 4269 with Union Carbide Corp., Nuclear Division (June 30, 1975), 40 pp, ORNL-SUB-4269-4.

2. Callahan, G. D. and Ratigan, J. L.: "Thermo/Viscoelastic Analysis of the Waste-Container Sleeve: II. Stress and Displacement Fields for the Room-and-Pillar Configuration", Technical Memorandum Report RSI-0021, Prepared for Holifield National Laboratory under Subcontract No. 4269 with Union Carbide Corp., Nuclear Division (June 30, 19े75), $40 \mathrm{pp}$, ORNL-SUB-4269-5.

3. Callahan, G. D., and Ratigan, J. L.: "Thermal Analyses of Spent Fuel Repositories in Bedded and Dome Salt", Technical Memorandum Report RSI-0054, Prepared for office of Waste Isolation under Subcontract No. 89Y-22303 with Union Carbide Corporation, Nuclear Division (May 4, 1977); 36 pp., Y/OWI/SUB-77/22303/4

4. Callahan, G. D.: "Summary of Conceptual Repository Analyses and Evaluations and In Situ Experiments for FY 1977", Project Summary Report RSI-0060, Prepared for Office of Waste Isolation under Subcontract No. 89Y-22303 with Union Carbide Corp., Nuclear Division (October 3, 1977), 28 pp., Y/OWI/SUB-77/22303/8.

5. Choi, D. S., Dahl, H. D., and von Schonfeldt, H.: "Design of Longwall Development Headings", Transactions of the Society of Mining Engineers, AIME, Vol. 258, pp. 358-363, (December, 1975).

6. Aisenstein, B., Denekamp, S., Hagati, G., and Tsur-Lavie, Y.: "Experimental and Theoretical Studies Concerning the Stability of Oil Storage Caverns Excavated in Chalk", The First International Symposium on Storage in Excavated Rock Caverns, ROCKSTORE 77, Stockholm, Sweden, (September, 1.977).

7. Ratigan, J. I.: "Evaluation of the Predictive Capability of the Finite Element Method: I. Project Salt Vault-Thermal Simulation", Technical Memorandum Report PSI-OOXX, Prepared for the office of Waste Isolation under Subcontract NO. 89Y-22303C with Union Carbide Corp., Nuclear Division (to be submitted).

8. Bradshaw, R. L., Perona, J. J. and Blomeke, J. O.: "Demonstration Disposal of High Level Radioactive Solids in Lyons, Kansas, Salt Mines: Background and Prelininary Design of Experimental Aspects", ORNL-TM-734, (January 10, 1964).

9. Bradshaw, R. L. and MCClain, W. C., Editors: "project Salt Vault: A Demonstration of the Disposal of High-Activity Solidified Wastes in Underground Salt Mines", CRNL-4555, (April, 1971). 
10. Hansen, F. D.: "Quasi-Static Strength and Creep Deformational Characteristics of Bedded Salt from the Carey Mine Near Lyons, Kansas", Technical Memorandum Report RSI-0067, Prepared for office of Waste Isolation under Subcontract No. 89Y-22303C with Union Carbide Corp., Nuclear Division (June 7, 1978), Y/OWI/SUB-77/22303/13, $150 \mathrm{pp}$.

11. Cheverton, R. D. and Turner, W. D.: "Thermal Analysis of the National Radioactive Repository: Progress.Through March, 1972", ORNL-4789, (September, 1972).

12. Desai, C. S. and Abel, J.F.: Introduction to the Finite Element Method, Van Nostrand Reinhold Company, 1972.

13: Obert, L. and Duval1, W. I.: Rock Mechanics and the Design of Structures in Rock, John Wiley and Sons, InC., 1967. 


\section{APPENDIX}

CORRELATION OF REPORT FIGURES WITH REFERENCE 9

RSI-0065 Report Figure

No.

4.1 .

4.2 .

4.3.

4.4 .

4.5.

4.6 .

4.7 .

4.8 .

4.9.

4.10.

4.11 .

4.12 .

4.13 .

4.14 .

4.15 .

4. 16 .

4.17.

4.18 .

4.19 .

4.20 .

4.21 .

4.22 .

4.23.

4.24.

4.25 .

4.26 .

4.27 .

4.28 .

4.29.
Page

17

18

18

22

23

23

24

24

25

25

28

28

29

30

30

31

31

32

32

33

33

34

35

35

36

37

37

.38

41
Reference 9 Report Figure

No.
11.57
$11.65 \& 11.66$
$11.86 \& 11.87$
$11.60 a$
$11.60 b$
11.81
11.81
$11.58 a$
$11.58 b$

Page

$11.86 \& 11.87$

$11.59 a$

$11.59 \mathrm{C}$

$11.59 a$

$11.59 \mathrm{C}$

210

$220-22 i$

246-247

215

215

240

240

211

211

246-247

212

213

212

213

$11.59 a$

212

$11.59 \mathrm{C}$

213

$11.80 \mathrm{C}$

239

$11.80 \mathrm{~b}$

238

$11.80 a$

238

$11.80 \mathrm{C}$

239

$11.80 \mathrm{~b}$

238

1.1. . 8חत

338

$11.80 \mathrm{C}$

239

$11.80 \mathrm{~b}$

238

$11.80 a$

238

$11.62 \& 11.63$

217

11.62

217

11.62

217

11.63 


\section{APPENDIX (CONT'D)}

\section{RSI-0065 Report Figure}

$\begin{array}{lr}\text { No. } & \text { Page } \\ 4.30 . & 42 \\ 4.31 . & 42 \\ 4.32 . & 43 \\ 4.33 . & 43 \\ 4.34 . & 44 \\ 4.35 . & 44 \\ 4.36 . & 45 \\ 5.1 . & 48 \\ 5.2 . & 48 \\ 5.3 . & 49 \\ 5.4 . & 49\end{array}$

\section{Reference 9 Report Figure}

$\begin{array}{cc}\text { No. } & \text { Page } \\ 11.63 & 217 \\ 11.62 & 217 \\ 11.62 & 217 \\ 11.63 & 217 \\ 11.63 & 217 \\ 11.82,11.83,11.84 & 242-244 \\ 11.82,11.83,11.84 & 242-244 \\ 11.60 a & 215 \\ 11.60 b & 215 \\ 11.81 & 240 \\ 11.81 & 240\end{array}$

